Dept. of Microbiology,

Faculty of Veterinary Medicine,

Al-Baath University, Syria Arab Republic.

\title{
EXPERMENTAL INFECTION STUDY OF NEOSPORA CANINUM STRAINS IN MICE
}

(With 5 Tables and 8 Photos)

\section{By}

W.A. AL-OBAIDII; M.M. KATRANJI and A. AL-KHALED

(Received at 15/12/2011)

$$
\text { وسن أمجد الغمج التجريبي بذراري البوغة الجديدة الكلبية في الفئران }
$$

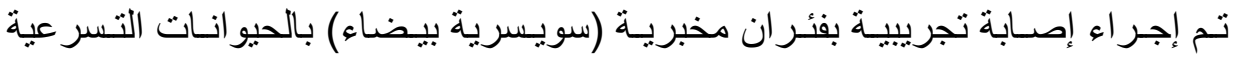

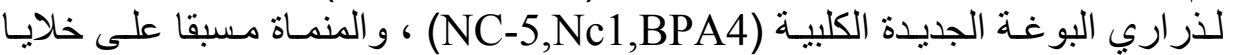

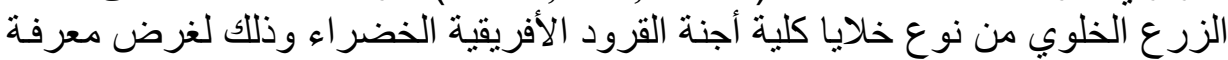

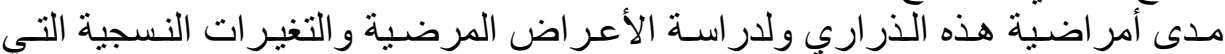

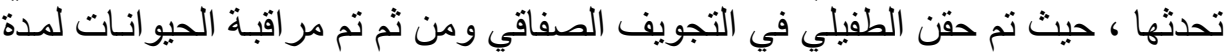

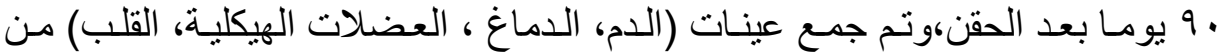

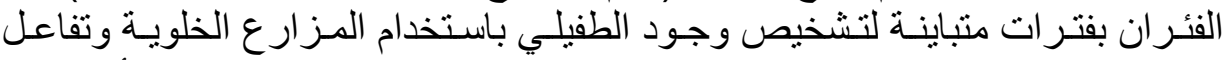

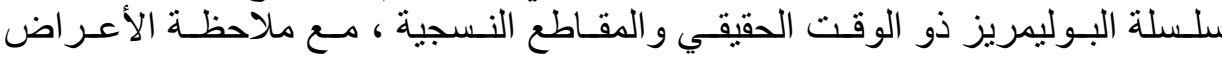

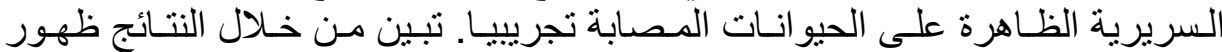

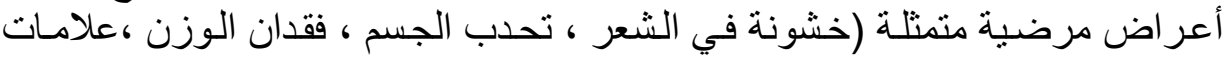

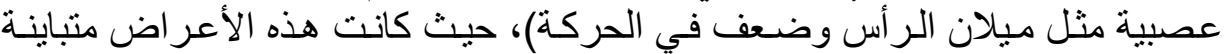

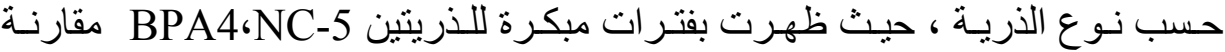

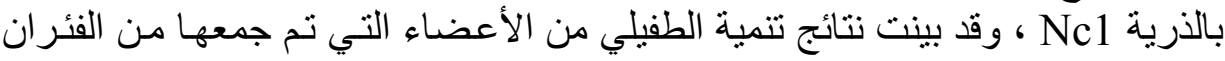

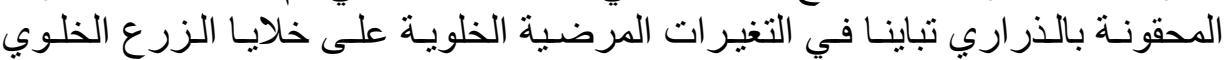

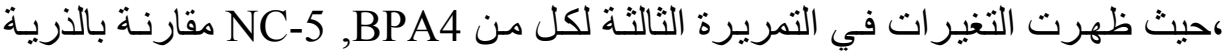

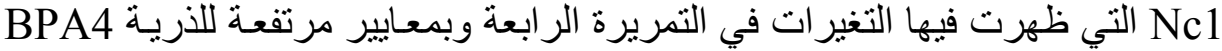

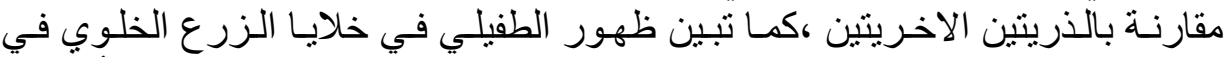

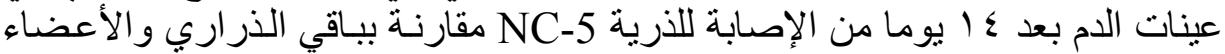

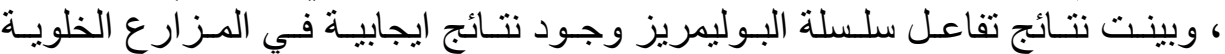

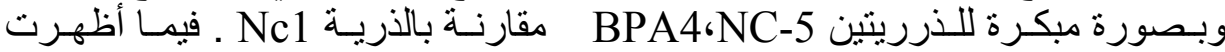

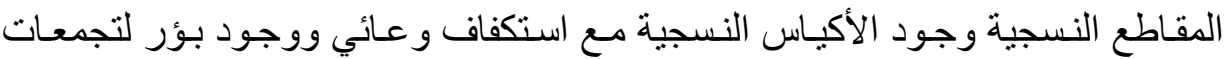

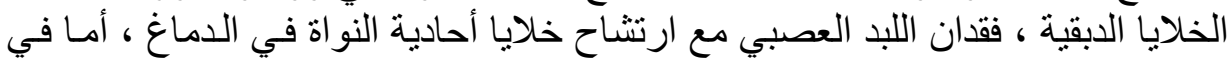




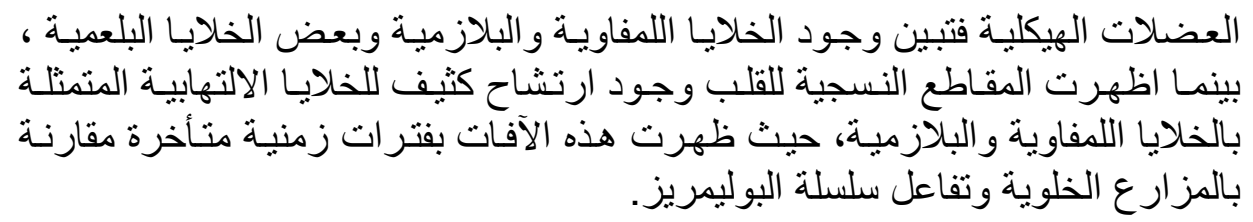

\section{SUMMARY}

In order to investigate the pathogencity, histopathological changes and clinical signs in white Swiss mice infected intraperitoneally with 3 different strains (NC-5, BPA4 and Nc1) of Neospora caninum, mice were kept under observation for 90 days after infection. The samples (blood, brain, skeletal muscle and heart) were collected at different times for diagnosis of the parasite by using Tissue culture (Vero cell, Real Time PCR and Histological sections) with observation of the clinical signs. The results showed clinical signs which manifested coat roughening, body hunching, weight loss, head tilting and impaired movement which were variable according to strain. The earlier signs appear in mice infected with NC-5 and BPA4 when comparison with mice infected with $\mathrm{Nc1}$, the result of propagation of parasite from the organs collected from infected mice showed variation in Cyto Pathic Effect (CPE) in vero cell, the CPE appear in the $3^{\text {rd }}$ passage in BPA4 and NC-5 when comparison withNc1 $\left(4^{\text {th }}\right)$ passage with higher titer in BPA4 when compared with other strains, the parasite appear in the blood sample in vero cell after 14 days of infected mice with NC-5 strain, the Real Time PCR result showed appearance of positive reaction in the infected cells culture infected with NC-5 and BPA4 strains. The histopathological changes appear presence of tissue cyst with prevascular cuffing and aggregation of glial cell, loss of Neuropil and infiltration of mononuclear cell in brain, the skeletal muscle showed presence of lymphocytes and plasma cell with some macrophage, the heart section showed heavy infiltration by inflammatory cells (plasma cell and lymphocytes), this histopathological changes appear delayed when compared with tissue culture and Real Time PCR.

Key words: Neospora caninum, mice, experimental infection. 


\section{INTRODUCTION \\ المقدمـة}

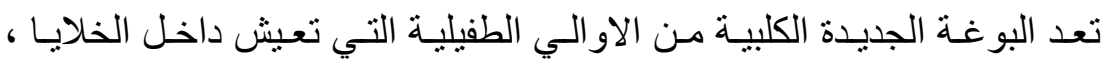

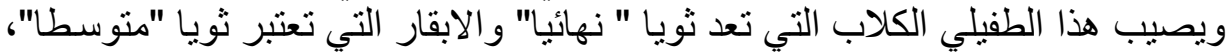

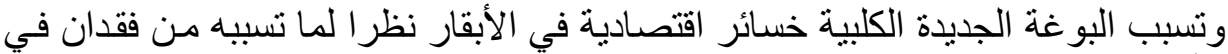

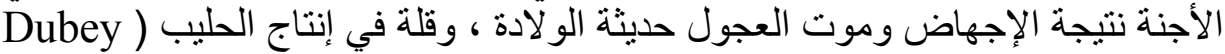

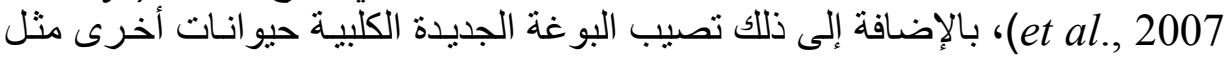

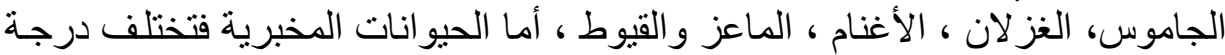

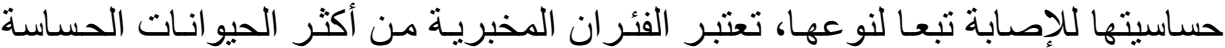

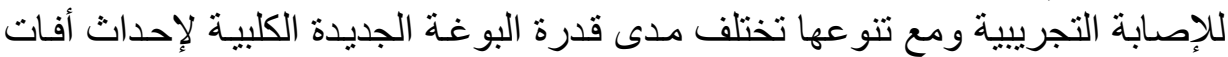

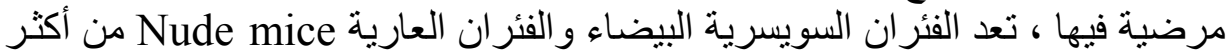

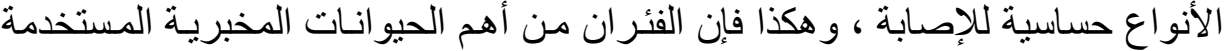

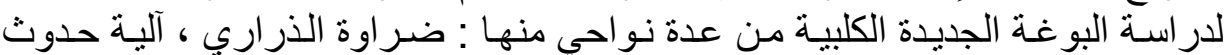

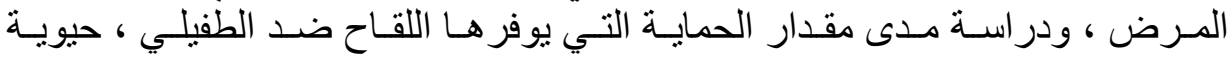

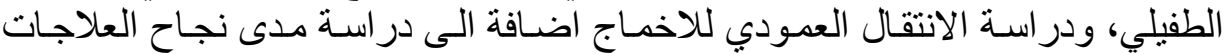

ضد الطفيلي، وكذلك الدر اسات المناعية و الدر اسات النسجية (Beck et al., 2009) .

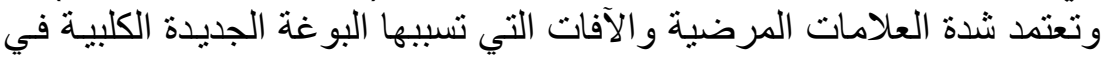

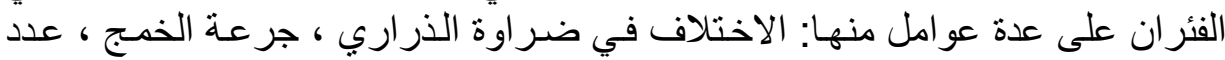

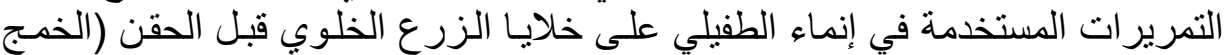

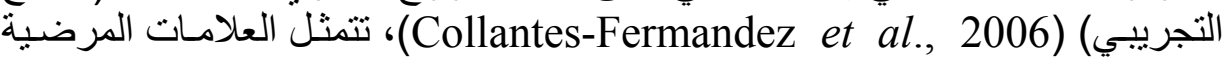
بخشونة في الثعر coat roughening ، و وتحدب الجسم body hunching ، و وفقدان

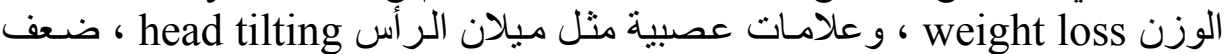

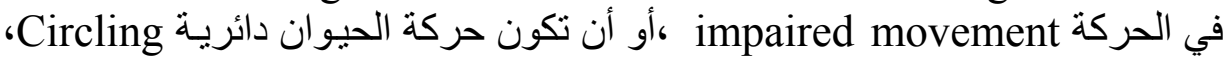

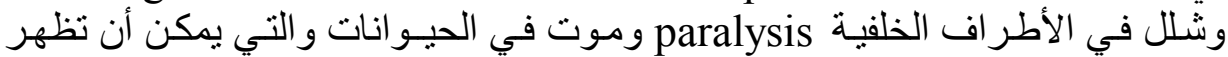

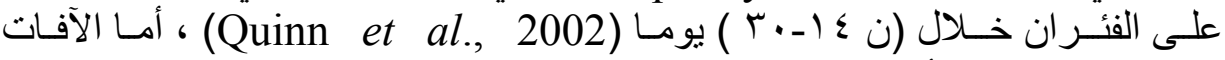

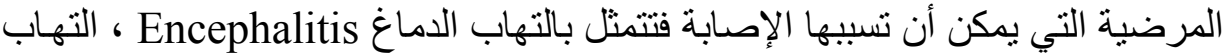

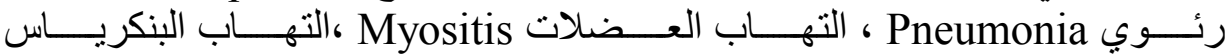

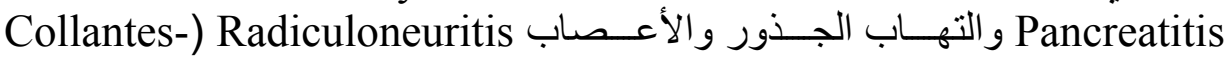
Fermandez et al., 2004

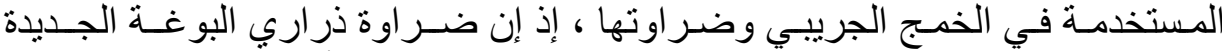

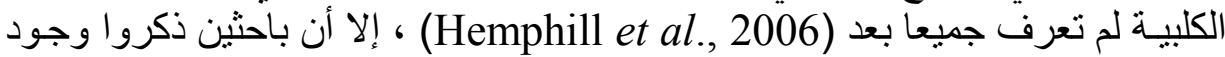

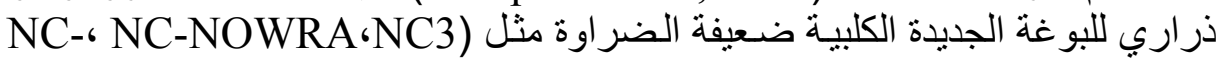
،BPA4،NC-5 فNc1 في حين عدت الـذراري (Nc3،Nc2 ، Spain 1H ، (Barber et al., 1995) ذراري مرتفعة الضراو (NC-Liverpool،BPA1

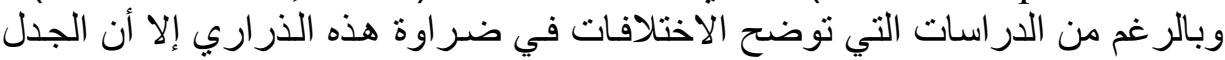


القائم هو عن مدى قدرتها على إحـداث الامـر اضية ونوعـهـا في الحيوانات المختلفة .(Rojo-Montejo et al., 2009)

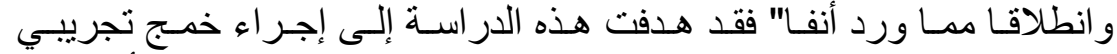

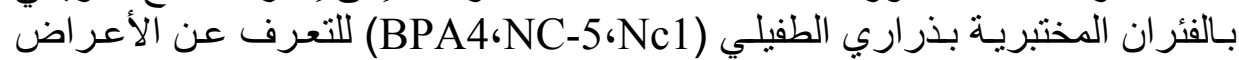

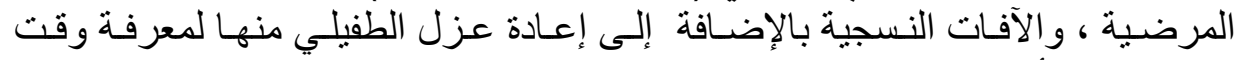

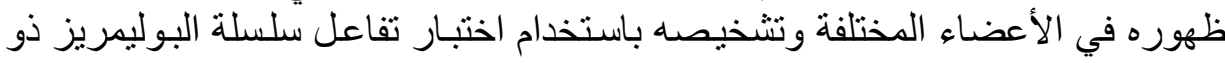

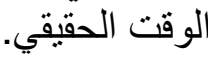

\section{MATERIALS and METHODS المواد وطر ائق البحث}

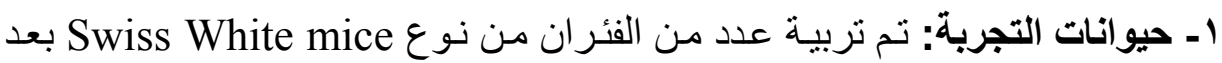

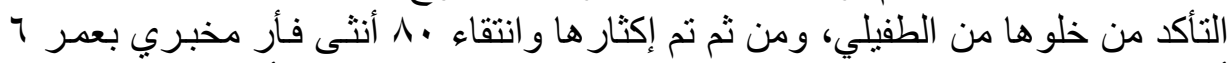

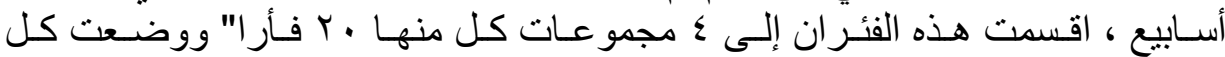

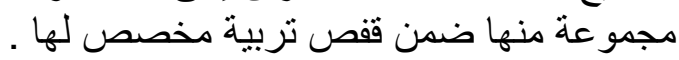

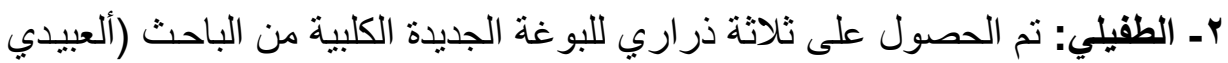

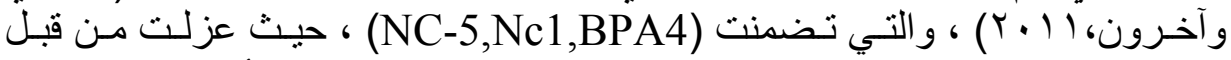

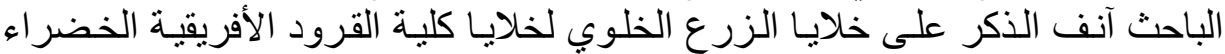

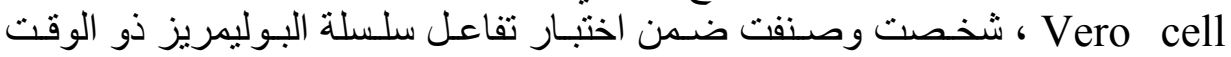

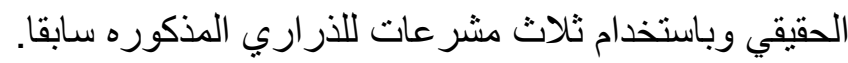

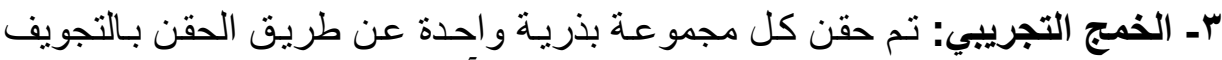

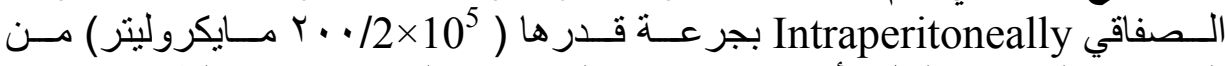

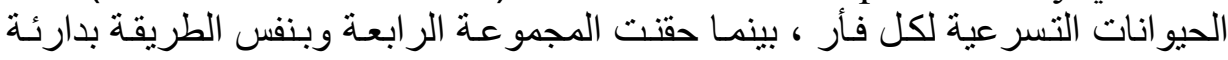

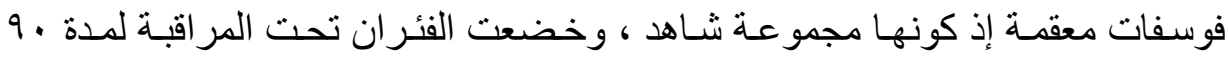

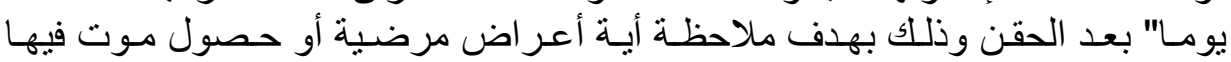
.(Chantal et al., 2004)

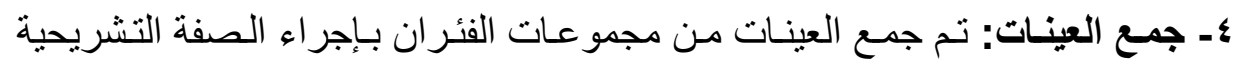

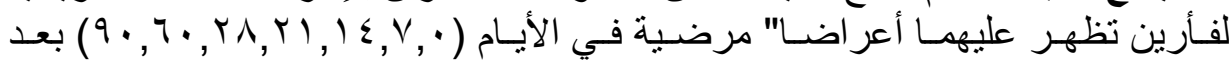

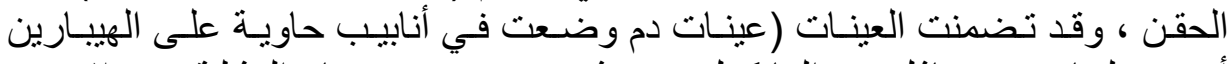

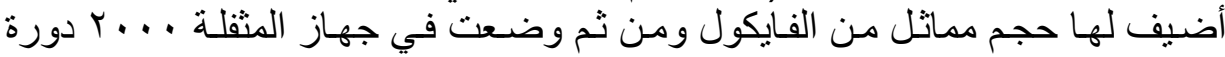

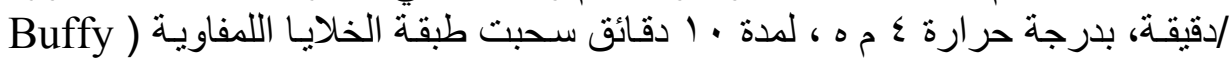
Coat

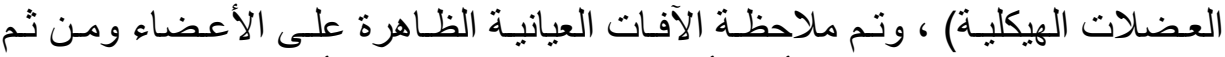

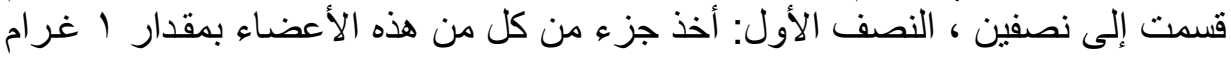

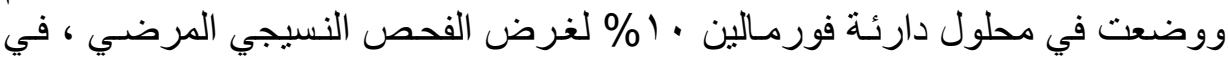

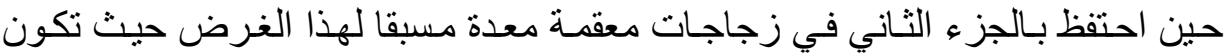




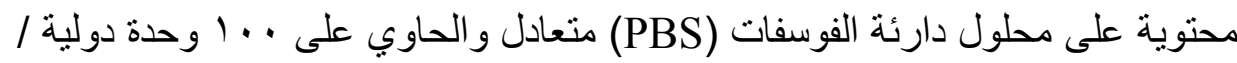

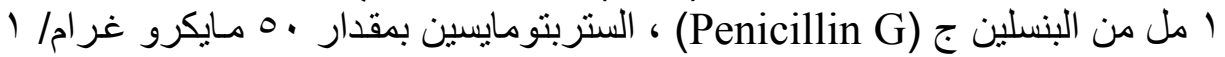

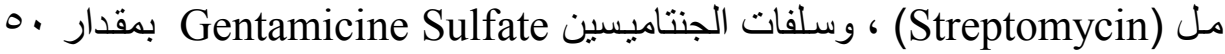

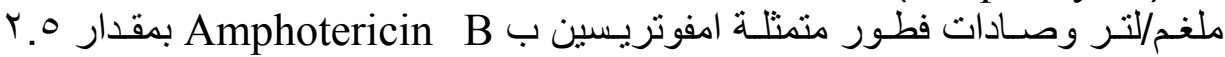

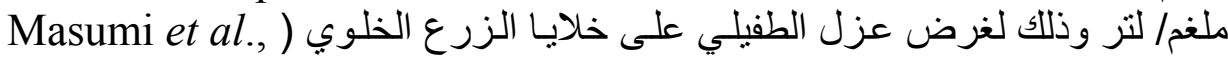
. (2000

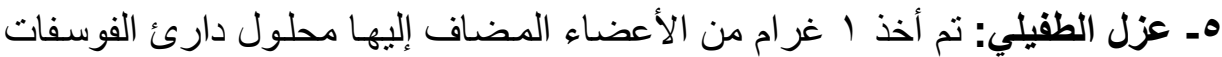

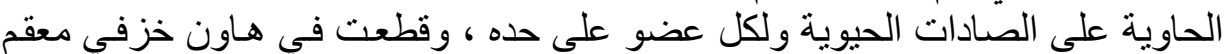

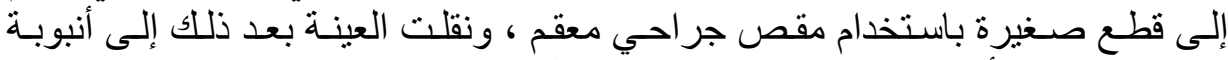

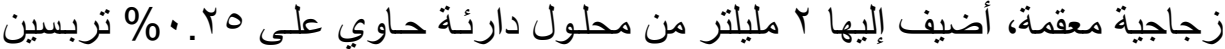

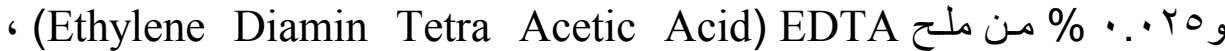

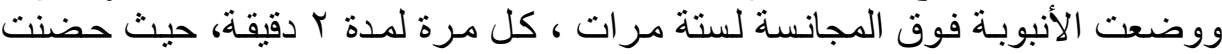

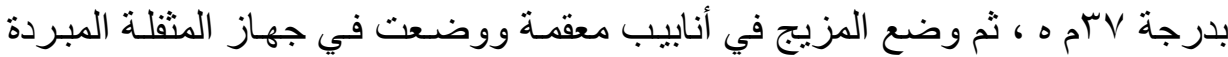

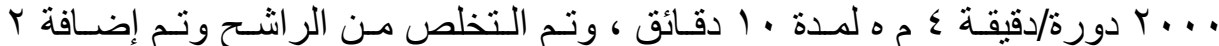
مليلتر مـن الوسط الزرعي للنمـ

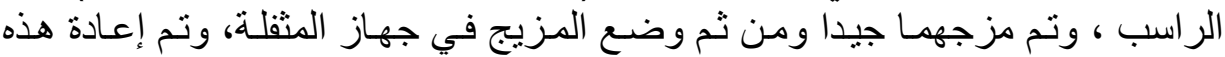

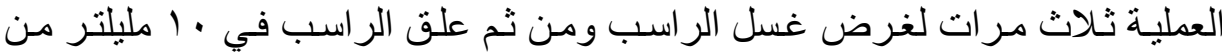

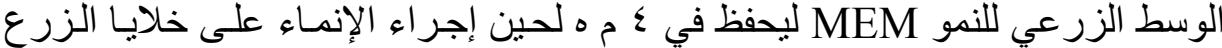
الخلوي (Nathalie, 2003).

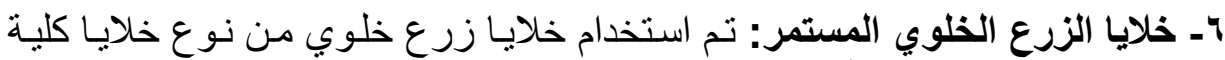

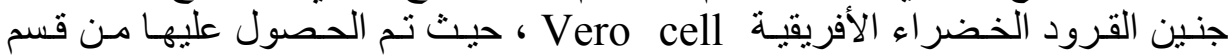

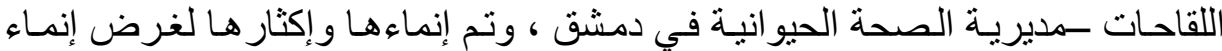
الطفيلي.

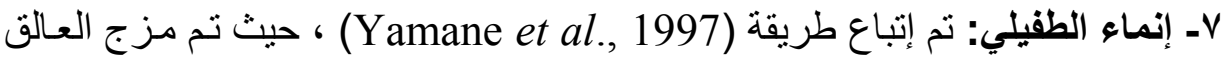

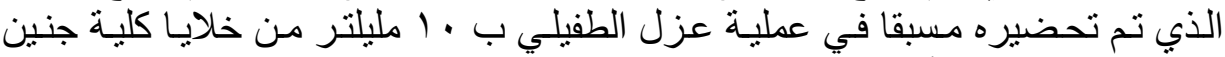

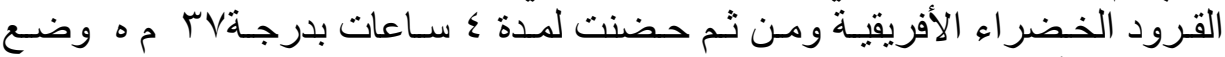

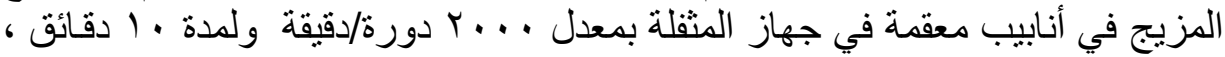

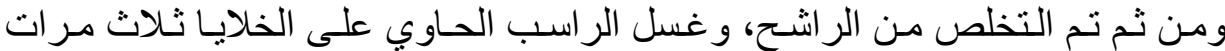

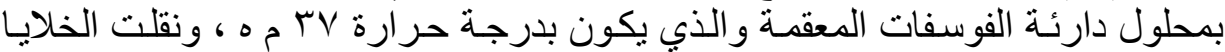

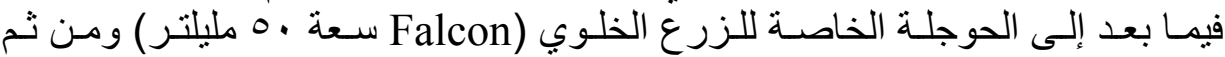
أضيف إليها وسط النمو (Growth media) الحاوي على • ( \% م مصل جنين بقري و

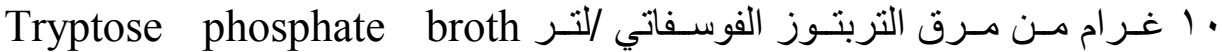

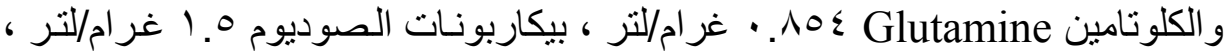

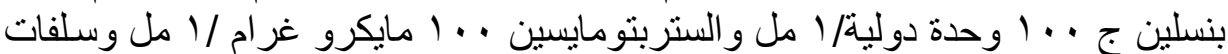

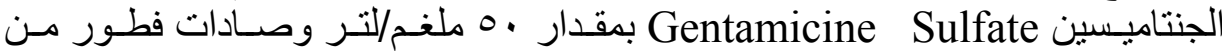

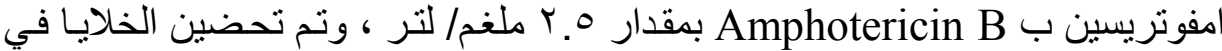




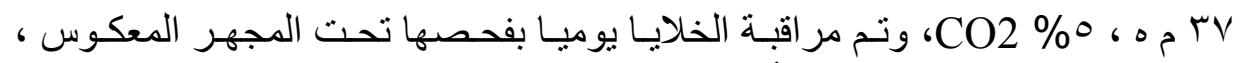

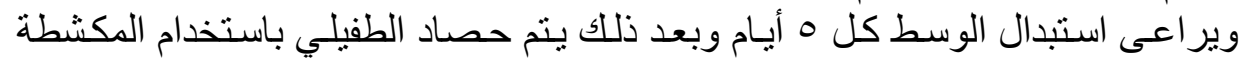

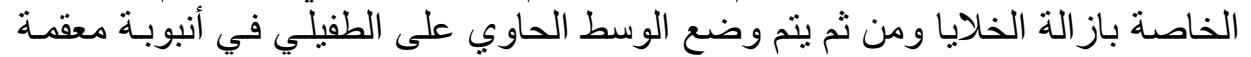

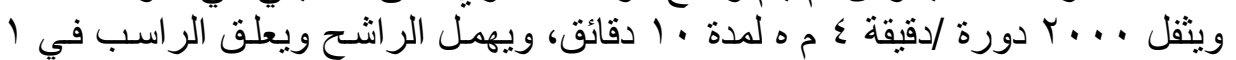

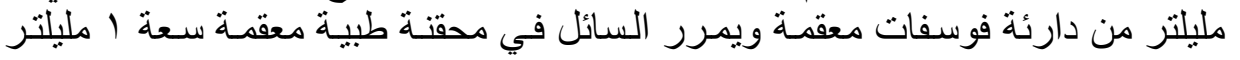

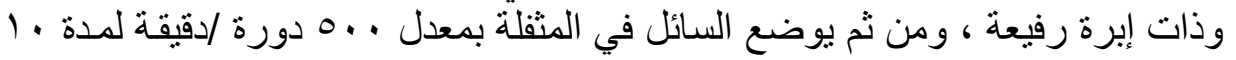

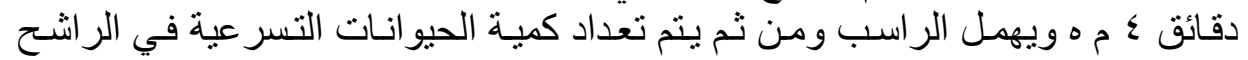

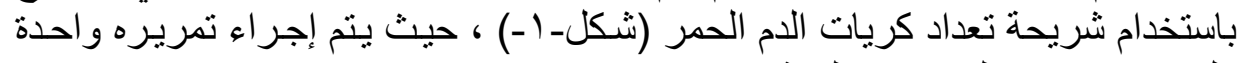

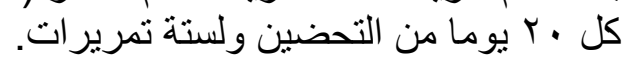

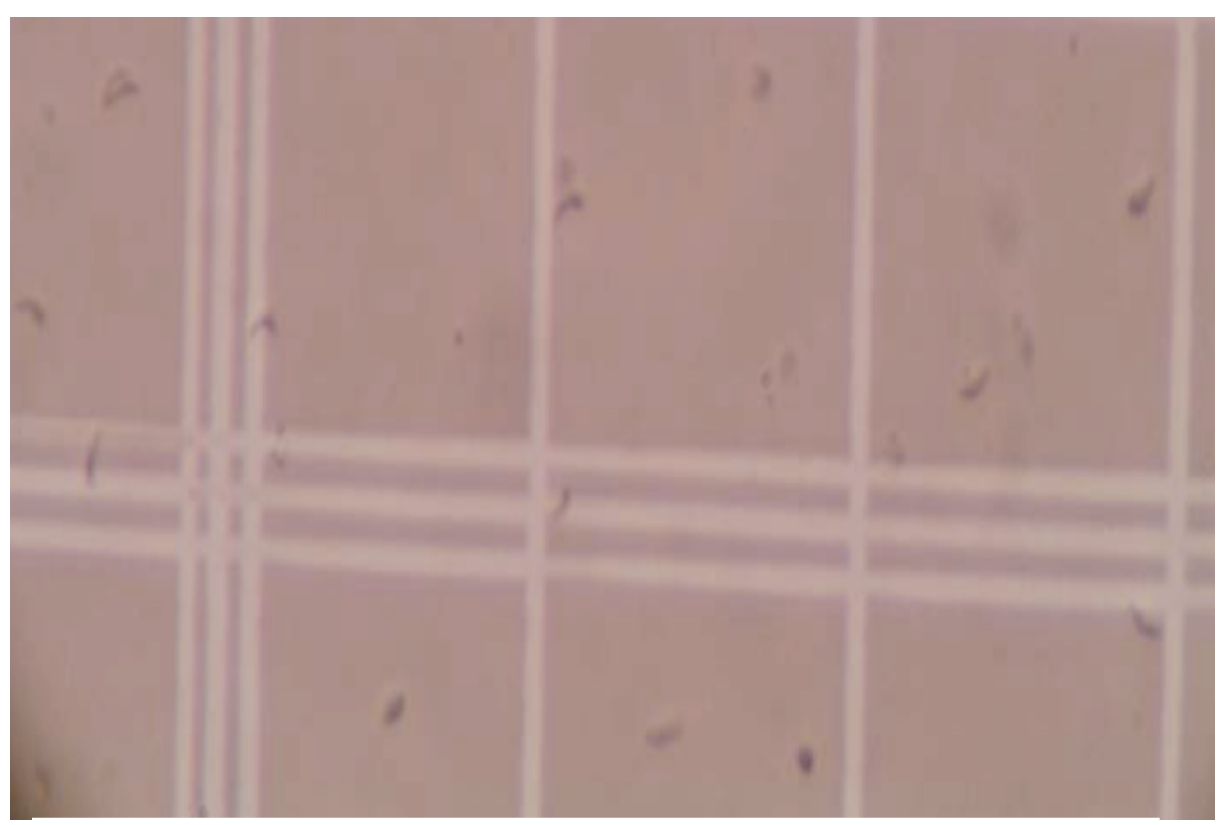
شكل ا: يبين الحيوانات التسر عية في شريحة عد كريات الدم الحمر

ᄉـ استخلاص ألانا DNA Extraction: تم إجر اء استخلاص ألدنا حسب تعليمات الثركة المصنعة للعتيدة (OMEGA bio kit). ـ تحضير المحاليل:

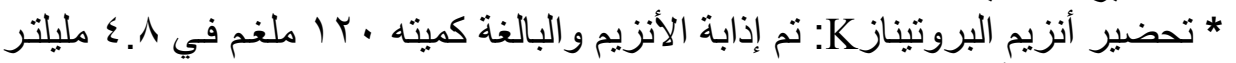
من دارئة حفظ أنزيم البروتيناز Proteinase storage buffer.

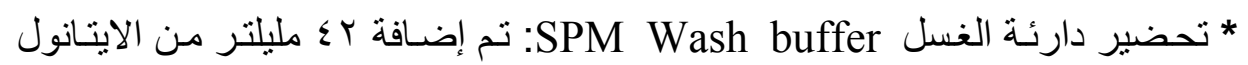
المطلق · . 1\% إلى • . مليلتر من دارئة الغسل لتكون جاهزة للاستخدام. 


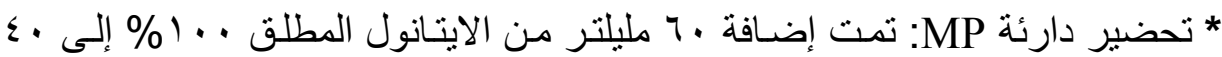
مليلتر من دارئة MP دارئة لتكون جاهزة للاستخدام.

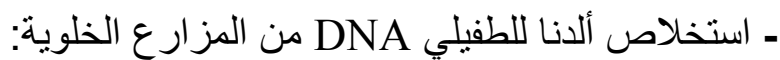

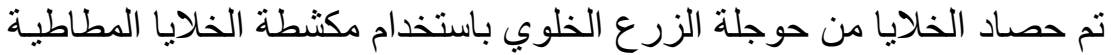
cell scraper

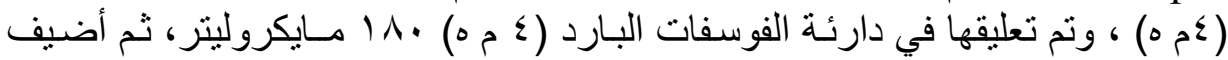

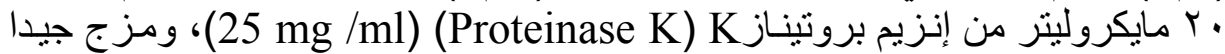

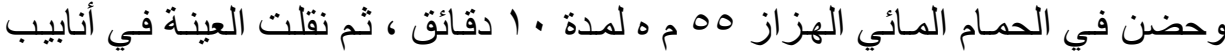

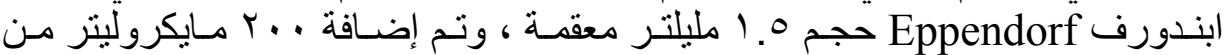

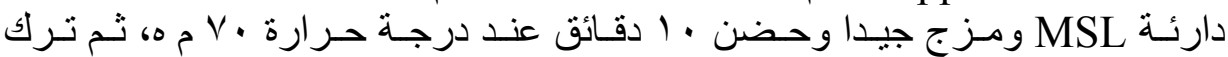

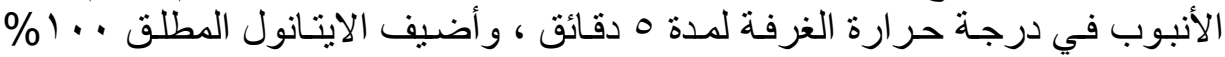

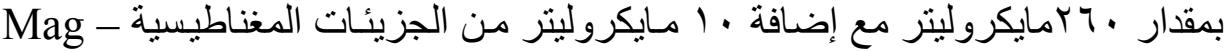

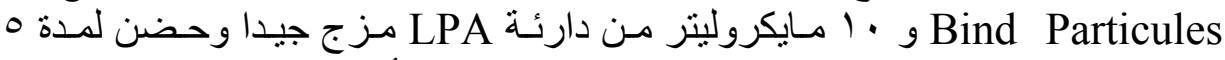

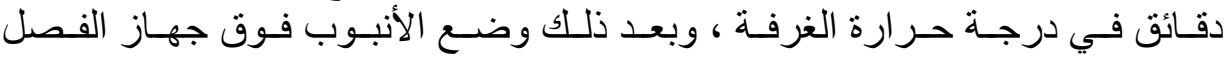

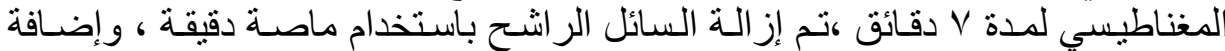

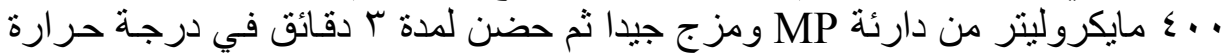

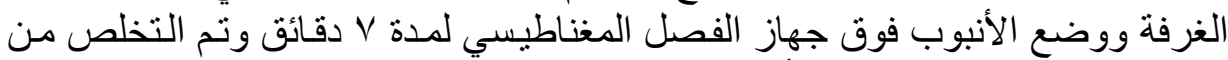

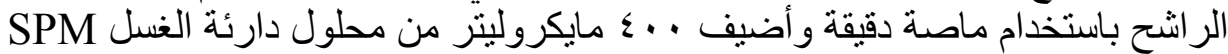
Wash Buffer

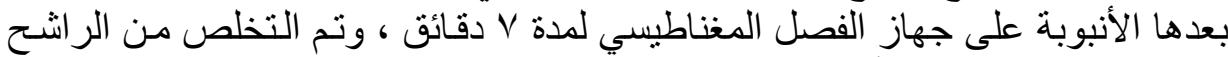

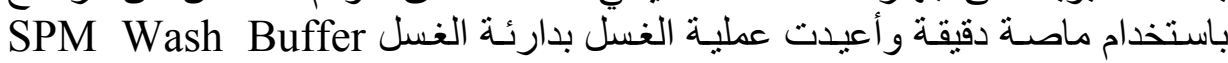

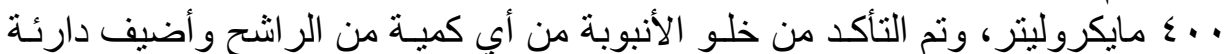

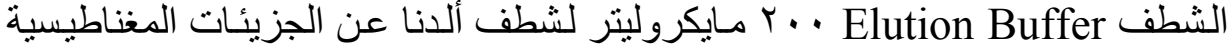

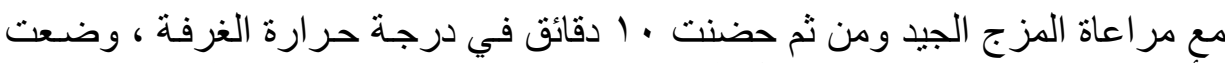

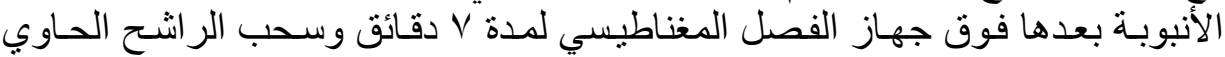

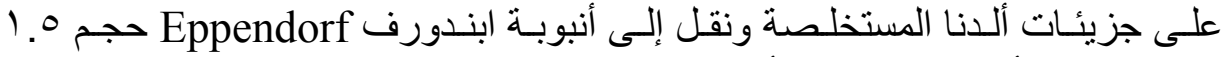
مليلتر معقــة أخرى، وحفظ الأنبوب في - •V م ه لحين إجر اء اختبـار تفاعل سلسلة

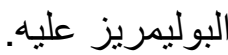

qـ تفاعل سلسلة البوليمريز ـذو الوقت الحقيقي Real Time PCR

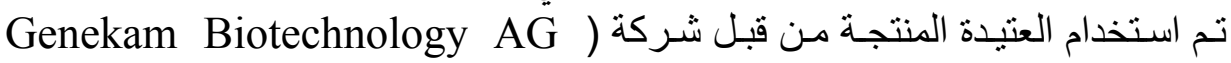

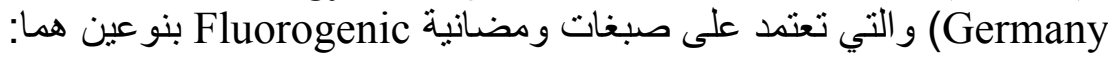

(6-carboxy tetramethyl rhodamine(reporter)) .(Carboxy -fluorescein (quencher)) 9ـ 1 ـ المحاليل والمواد المستخدمة في تفاعل البوليمريز 
عبارة عن مزيج تفاعل يحتوب على كل مكونـات التفاعل مـع المشر عات وقالب والب ألدنا

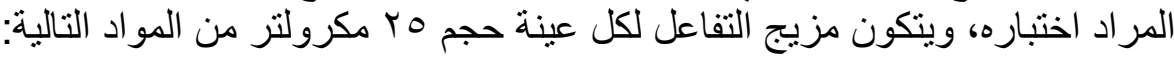

\begin{tabular}{|c|c|c|c|}
\hline 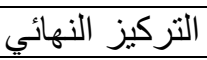 & الكمية(ul) & 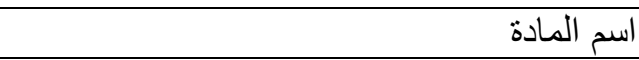 & $ت$ \\
\hline $1 \mathrm{X}$ & Y.o & 10X PCR Buffer & -1 \\
\hline $200 \mathrm{uM}$ & 0.5 & dNTPs(dATP, dCTP, dGTP, \& dTTP & $-Y$ \\
\hline $1.5 \mathrm{mM}$ & r.Yo & $\operatorname{Mgcl} 2$ & $-r$ \\
\hline 2.5 units & 0.125 & Taq DNA-Polymerase & $-\varepsilon$ \\
\hline $100 \mathrm{nM}$ & 0.25 & Dyes & -0 \\
\hline $800 \mathrm{nM}$ & $\cdot r$ & Primer A & -7 \\
\hline $800 \mathrm{nM}$ & $\cdot . Y$ & Primer B & $-V$ \\
\hline - & 0 & DNA Template & $-\Lambda$ \\
\hline- & Ir.9Vo & RNA Free Water & -9 \\
\hline
\end{tabular}

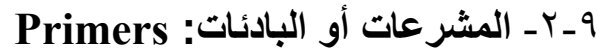

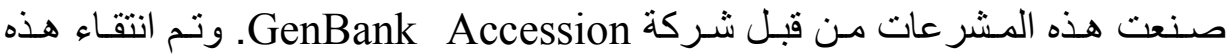

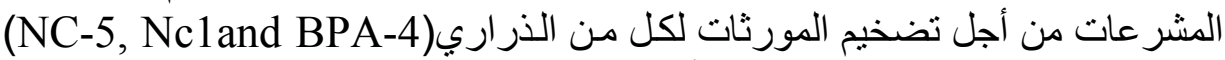
(Nathalie, 2003)

\begin{tabular}{|c|c|c|c|}
\hline الحجم(bp) & تسلسل البادئة الور اثي ه'بـ' & 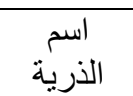 & 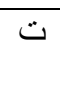 \\
\hline 17 & $\begin{array}{l}1 \text { 'rCACAAGTCGCACGGAGGTCA'。 } \\
' r \text { AAGGAGAACGCTTCGTAACAA'。 }\end{array}$ & NC-5 & 1 \\
\hline rTV & $\begin{array}{c}\text { 'rCACACACTTGCCCACTTGGCTCCCT'。 } \\
\text { 'rACCATCGCCACTCTCCACCCTATGCAC'。 }\end{array}$ & BPA-4 & $r$ \\
\hline TYV & $\begin{array}{l}\text { 'rAATGTCCTAACCTGCGTGACCC 'o } \\
\text { 'rTCTTCTGCATCCAACTGACCGCTC '。 }\end{array}$ & $\mathrm{Nc1}$ & $r$ \\
\hline
\end{tabular}

q_r- خطوات عمل تفاعل سلسلة البوليمريز ذو الوقت الحقيقي:

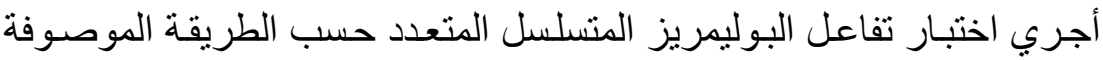

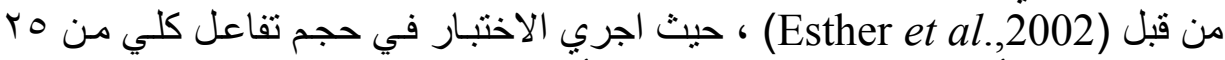

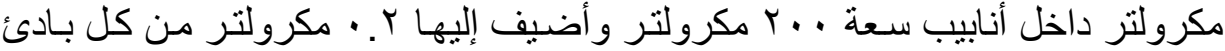

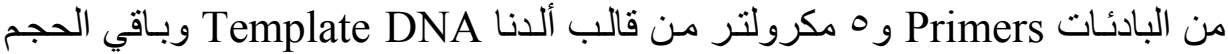

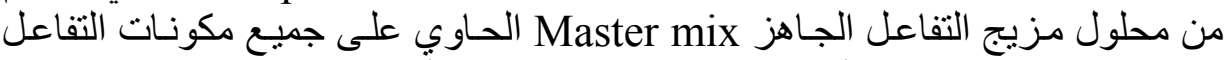

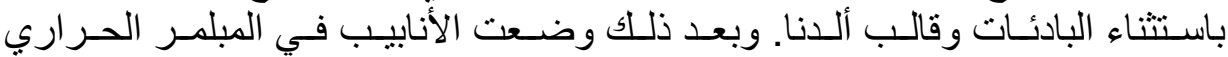
(Thermocycler)

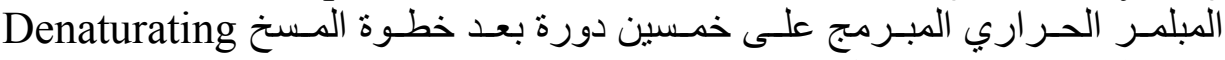

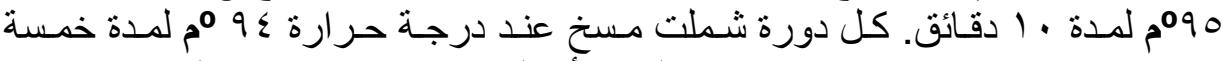

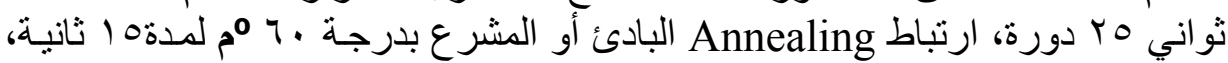




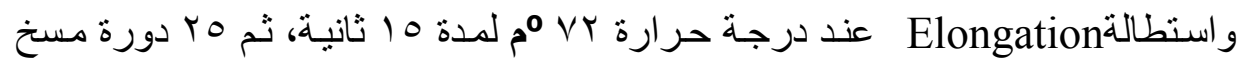

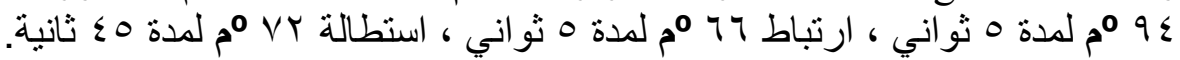

، تم إجر اءه حسب الطريقة التهي ذكر هـا (Shibahara et al., 1999)

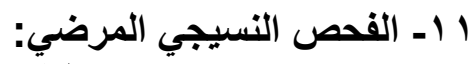
باستخدام صبغة الهيماتوكسلين و الايوسين.

\section{RESULTS}

$$
\text { النتائسـج }
$$

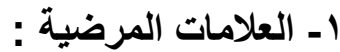

تبين من خلال مر اقبـة مجاميع الفئر ان لمدة .9 بومـا و التي خمجت بذر اري

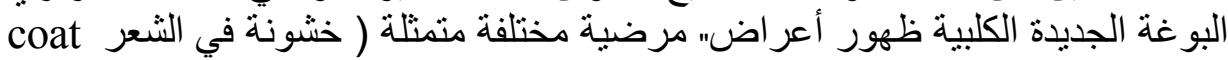

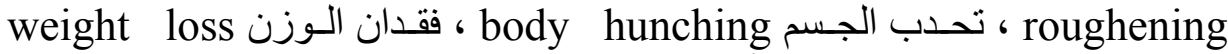

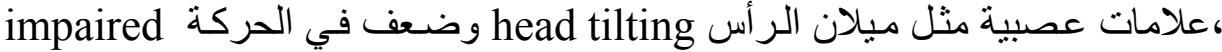
(الأشكال ) (movement

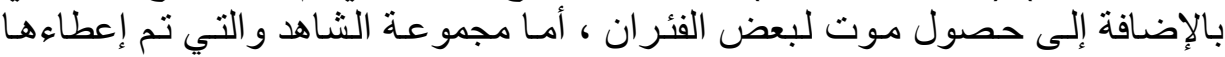

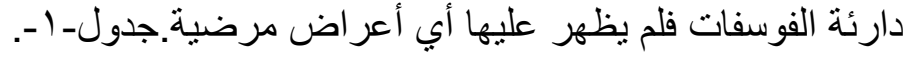

جدول ا : ييبين الأعر اض المرضية الظـاهرة على مجاميع الفئران المحقونـة بذر اري

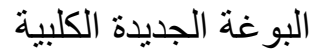

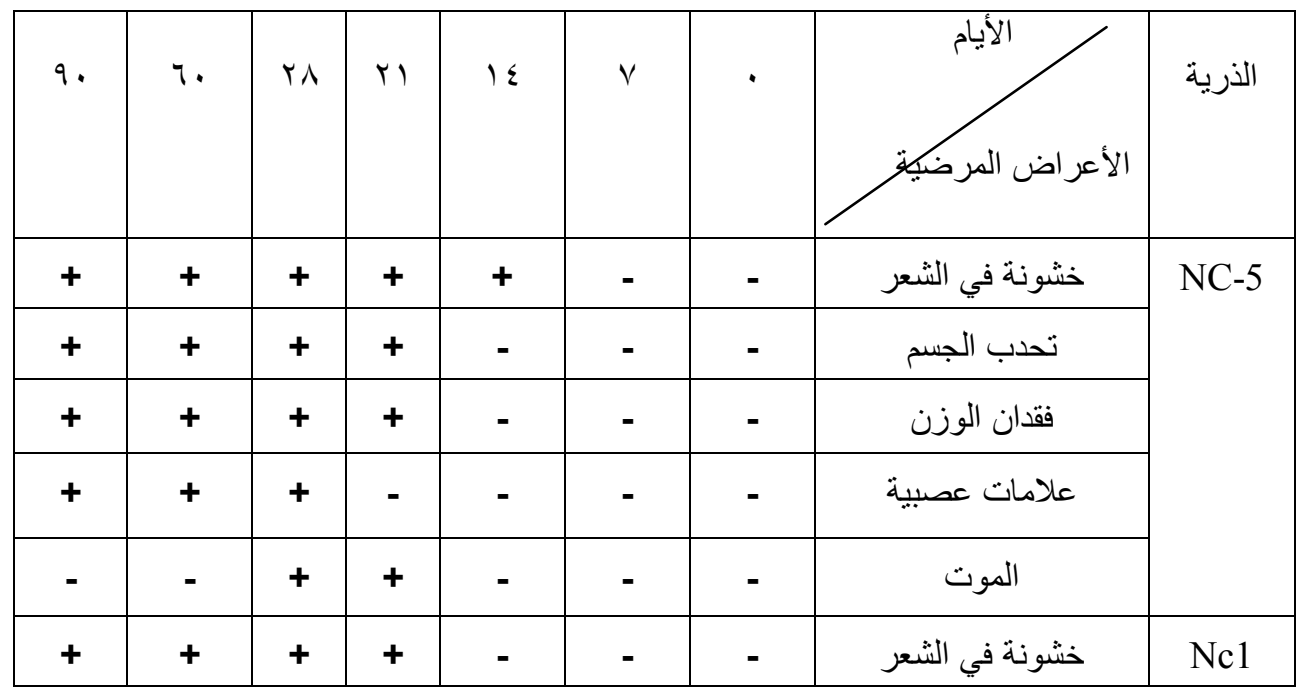


Assiut Vet. Med. J. Vol. 58 No. 132 January 2012

\begin{tabular}{|c|c|c|c|c|c|c|c|c|}
\hline+ & + & + & - & - & - & - & تحدب الجسم & \\
\hline+ & + & + & + & - & - & - & فقدان الوزن & \\
\hline- & + & - & - & - & - & - & علامات عصبية & \\
\hline- & - & + & - & - & - & - & الموت & \\
\hline+ & + & + & + & + & - & - & خشونة في الثشعر & \multirow[t]{5}{*}{ BPA4 } \\
\hline+ & + & + & + & - & - & - & تحدب الجسم & \\
\hline+ & + & + & - & - & - & - & فقدان الوزن & \\
\hline+ & + & - & - & - & - & - & علامات عصبية & \\
\hline- & - & - & + & - & - & - & الموت & \\
\hline
\end{tabular}

العلامــات التاليـة تعنـي (-) عـدم ظهـور ألأعـر اض المرضـية المبينـة ،(+) ظهـور الأعر اض المرضية المبينة

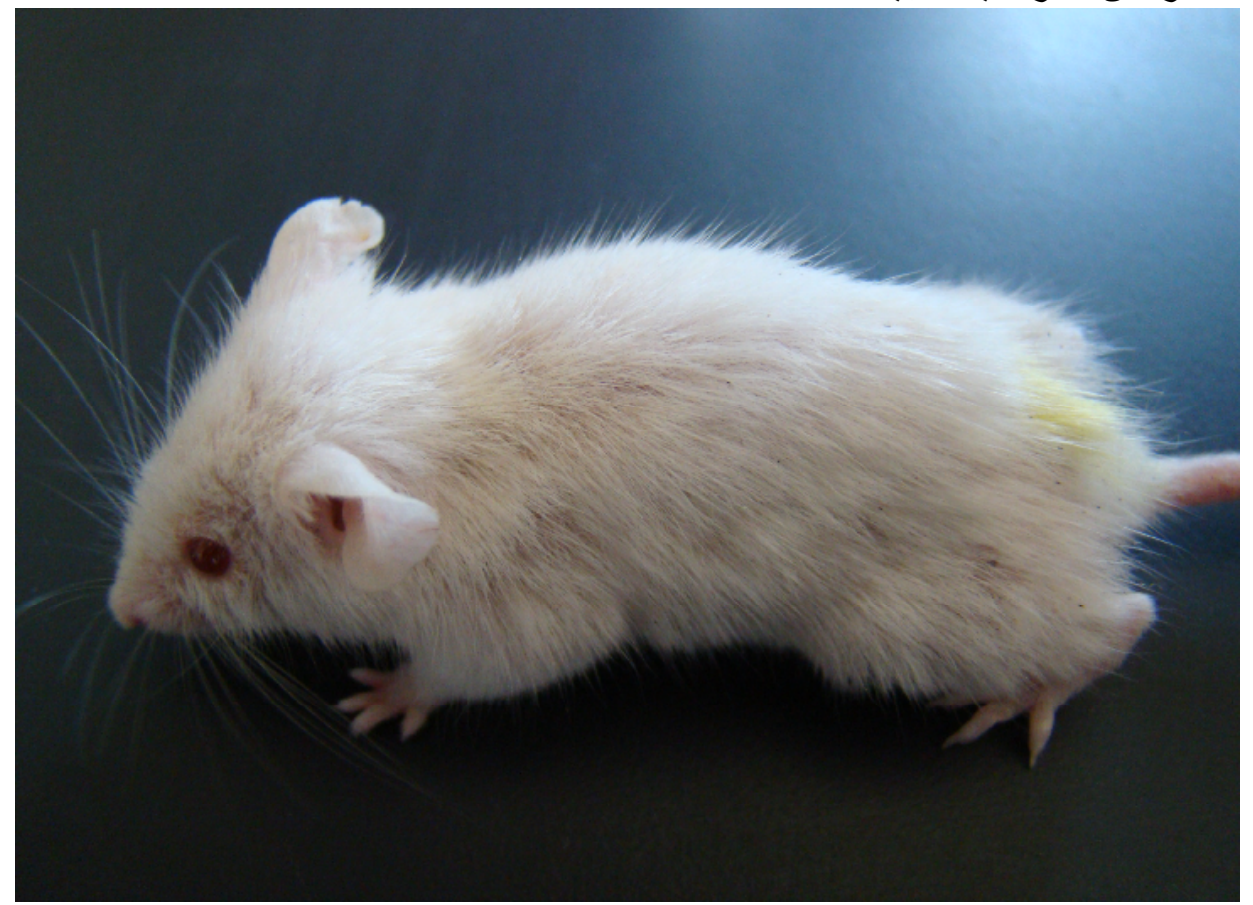

شكل ا : يبين الضعف العام وخشونة الثعر في الفئر ان المحقونة بالطفيلي 


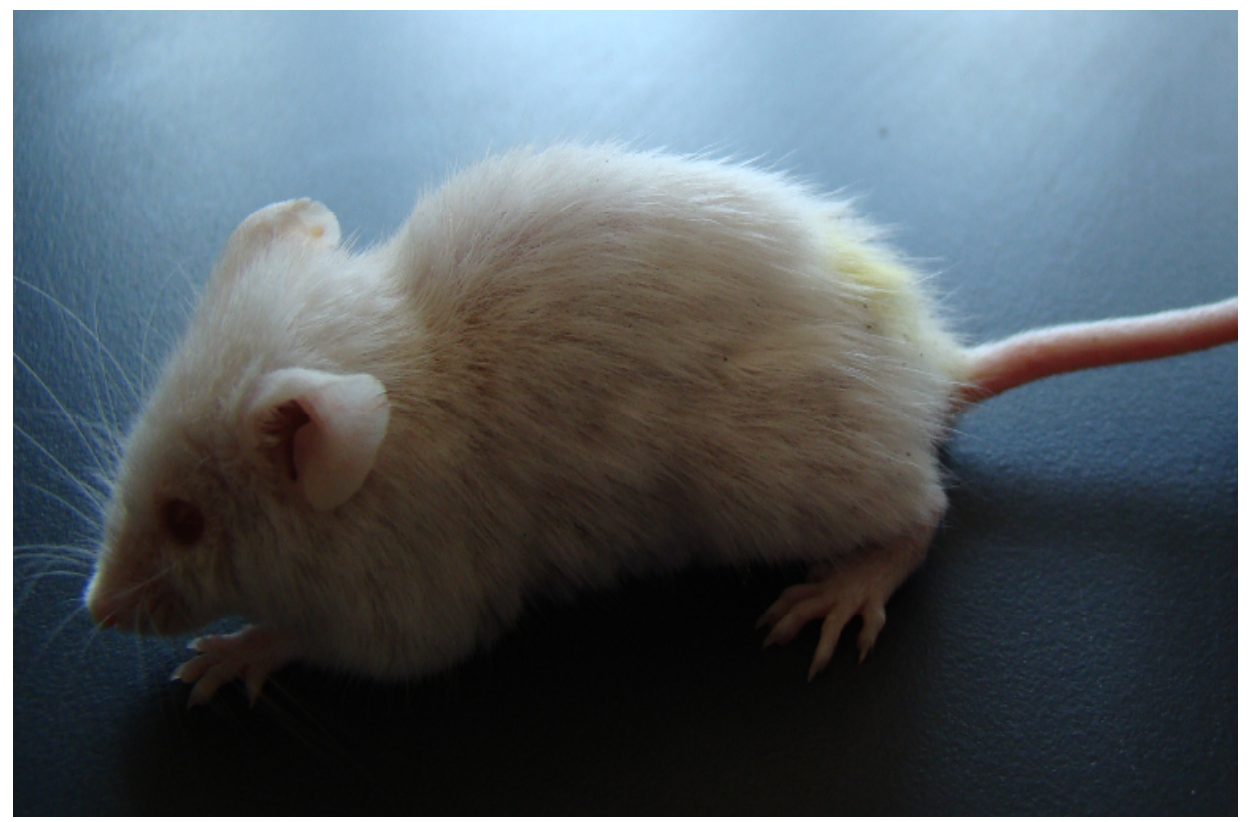

شكل ץ : يبين تحدب الظهر في الفئران المحقونة بالطفيلي

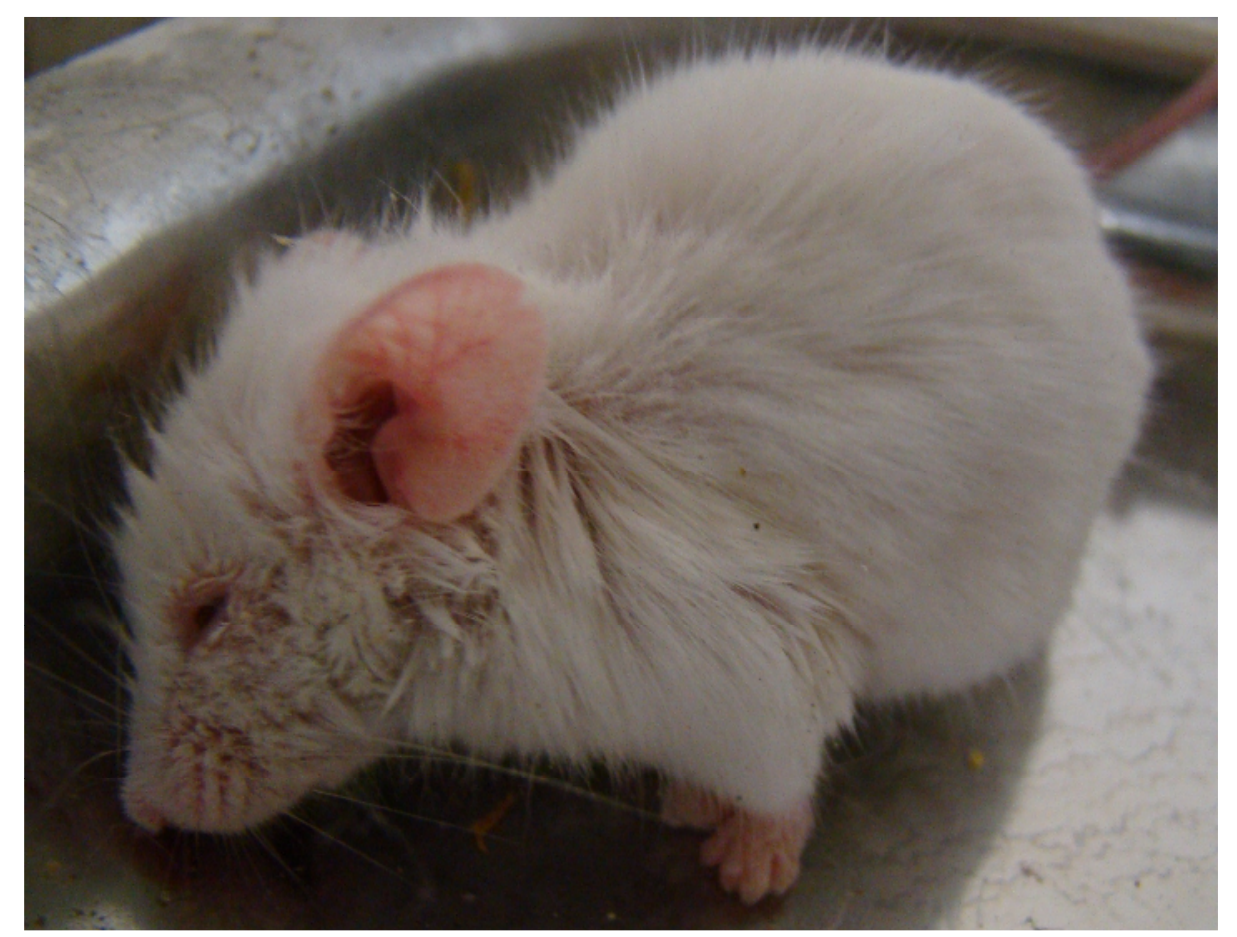

شكل بّ: يبين ميلان الر أس في الفئران المحقونة بالطفيلي 


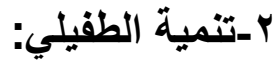

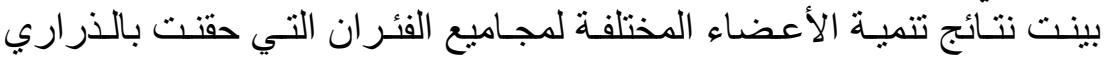

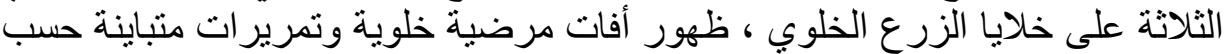

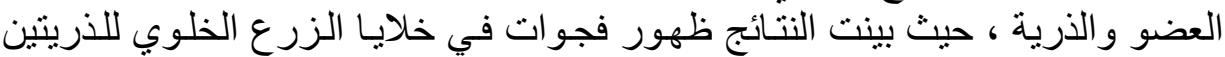

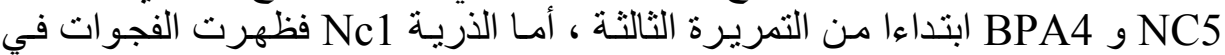

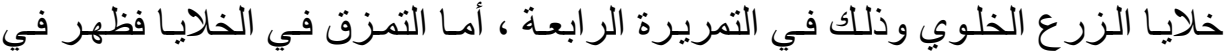

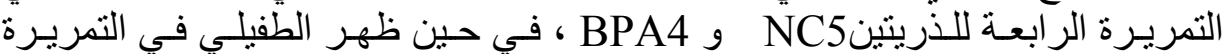

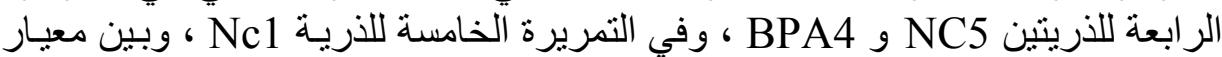

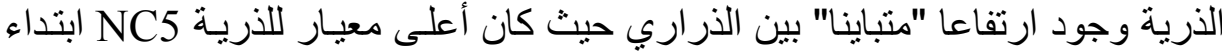

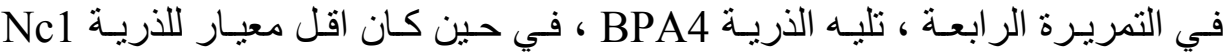

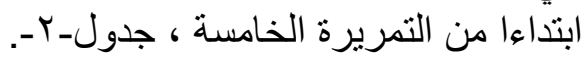

جدول ب : يبين التغيرات المرضية الخلويـة Cyto Pathic Effect على خلايـا الزرع

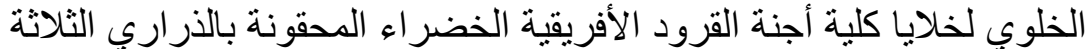

\begin{tabular}{|c|c|c|c|c|c|}
\hline معيار الذرية/ · مايكروليتر & ظهور الطفيلي & ت الخلايا & فجوات & وي & الذرية \\
\hline - & - & - & - & الأولى & \multirow[t]{6}{*}{$\mathrm{NC5}$} \\
\hline- & - & - & - & الثانية & \\
\hline- & - & - & + & الثالثة & \\
\hline $2 \times 10^{2}$ & + & + & + & الر ابعة & \\
\hline $2 \times 10^{3}$ & + & + & + & الخامسة & \\
\hline $2 \times 10^{5}$ & + & + & + & السادسة & \\
\hline- & - & - & - & الأولى & \multirow[t]{6}{*}{$\mathrm{Nc} 1$} \\
\hline- & - & - & - & الثانية & \\
\hline- & - & - & - & الثالثة & \\
\hline- & - & - & + & الر ابعة & \\
\hline $2 \times 10^{2}$ & + & + & + & الخامسة & \\
\hline $2 \times 10^{3}$ & + & + & + & السادسة & \\
\hline- & - & - & - & الأولى & \multirow[t]{3}{*}{ BPA4 } \\
\hline- & - & - & - & الثانية & \\
\hline- & - & - & + & الثالثة & \\
\hline
\end{tabular}


Assiut Vet. Med. J. Vol. 58 No. 132 January 2012

\begin{tabular}{|c|c|c|c|c|}
\hline $2 \times 10^{3}$ & + & + & + & الر ابعة \\
\hline $2 \times 10^{4}$ & + & + & + & الخامسة \\
\hline $2 \times 10^{6}$ & + & + & + & السادسة \\
\hline
\end{tabular}

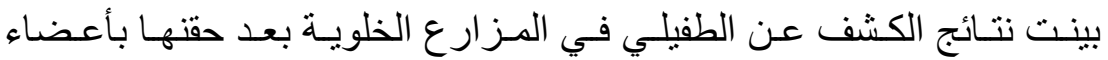

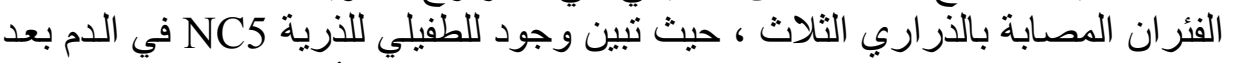

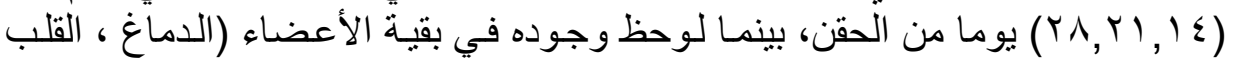

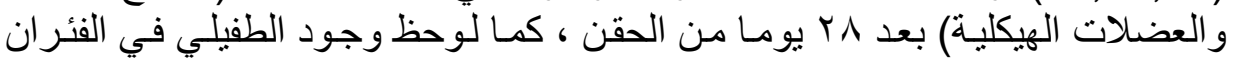

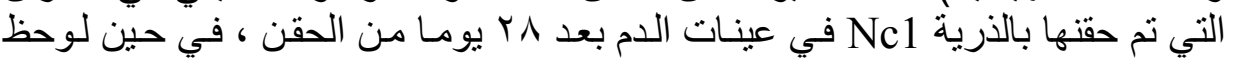

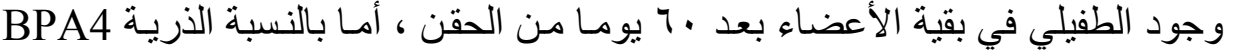

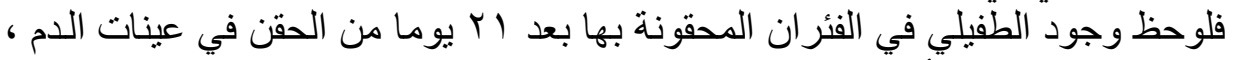

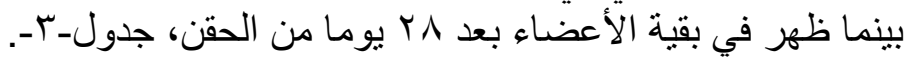

جدول r : يبين ظهور الطفيلي في الأعضاء المختلفة للفئران قبل وبعد الحقن بالذراري الثلاث باستخدام المزارع الخلوية الاعنية

\begin{tabular}{|c|c|c|c|c|c|c|c|c|}
\hline 9 . & 7. & rᄉ & r) & $1 \varepsilon$ & V & . & & \\
\hline+ & + & + & - & - & - & - & الدماغ & \multirow[t]{5}{*}{ NC5 } \\
\hline+ & + & + & - & - & - & - & القلب & \\
\hline+ & + & + & - & - & - & - & العــــــــات & \\
\hline & & & & & & & الهيكلية & \\
\hline- & - & + & + & + & - & - & الد الدم & \\
\hline+ & + & - & - & - & - & - & الدماغ & \multirow[t]{5}{*}{$\mathrm{Nc1}$} \\
\hline+ & + & - & - & - & - & - & القلب & \\
\hline+ & + & - & - & - & - & - & العــــــــات & \\
\hline & & & & & & & الهيكلية & \\
\hline- & - & + & - & - & - & - & الدم الدم & \\
\hline+ & + & + & - & - & - & - & الدماغ & \multirow[t]{5}{*}{ BPA4 } \\
\hline+ & + & + & - & - & - & - & القلب & \\
\hline+ & + & + & - & - & - & - & العــــــــــلات & \\
\hline & & & & & & & الهيكلية & \\
\hline- & - & - & + & - & - & - & الدم الدم & \\
\hline
\end{tabular}

r- تفاعل سلسلة البوليمريز: 


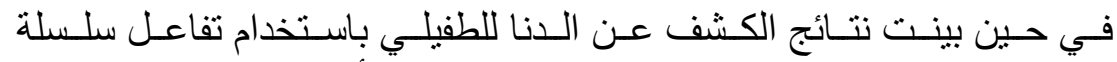

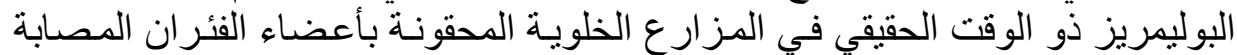

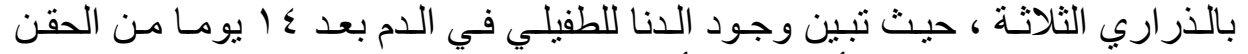

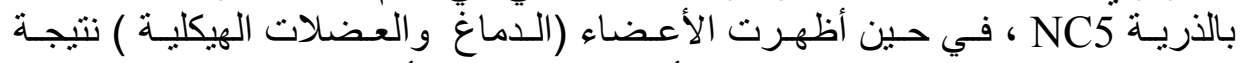

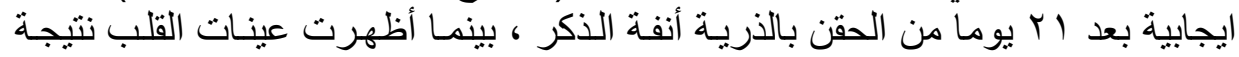

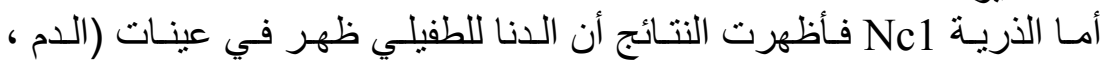

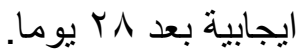

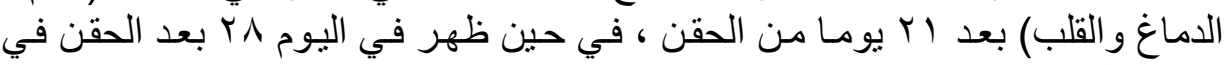

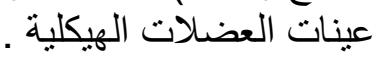
و أظهرت نتائج الكثف عن عن الدنا للطفيلي للذريـة BPA4 وجود نتائج ايجابية

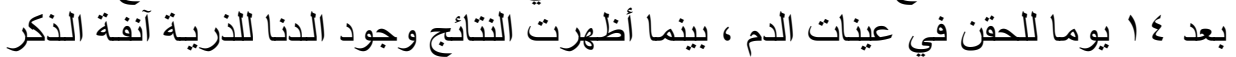

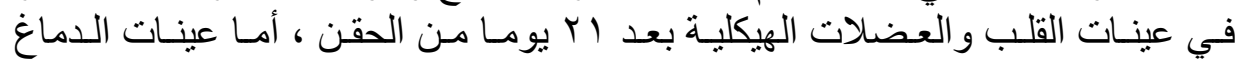

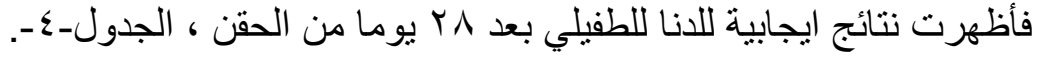

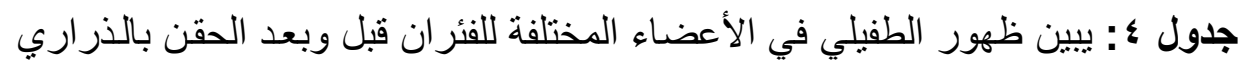

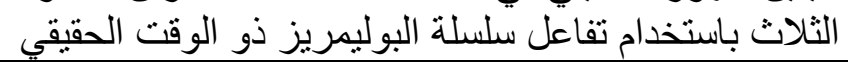

\begin{tabular}{|c|c|c|c|c|c|c|c|c|}
\hline 9. & 7. & rᄉ & YI & $1 \varepsilon$ & V & . & & \\
\hline+ & + & + & + & - & - & - & الاماغ & \multirow[t]{4}{*}{ NC5 } \\
\hline+ & + & + & - & - & - & - & القلب & \\
\hline+ & + & + & + & - & - & - & العـيكلية العلات & \\
\hline- & - & + & + & + & - & - & الدم & \\
\hline+ & + & + & + & - & - & - & الدماغ & \multirow[t]{4}{*}{$\mathrm{Nc1}$} \\
\hline+ & + & + & + & - & - & - & القلب & \\
\hline+ & + & + & - & - & - & - & العهيكلية العلات & \\
\hline- & - & + & + & - & - & - & الدم & \\
\hline+ & + & + & - & - & - & - & الدماغ & \multirow[t]{4}{*}{ BPA4 } \\
\hline+ & + & + & + & - & - & - & القلب & \\
\hline+ & + & + & + & - & - & - & العهيكلية العلات & \\
\hline- & - & + & + & + & - & - & الدم & \\
\hline
\end{tabular}

ع - الفحص النسيجي المرضي: 


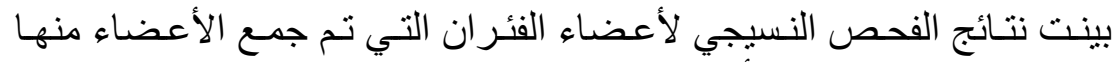

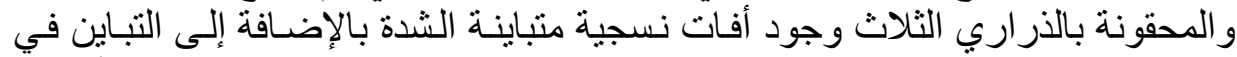

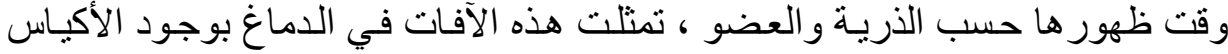

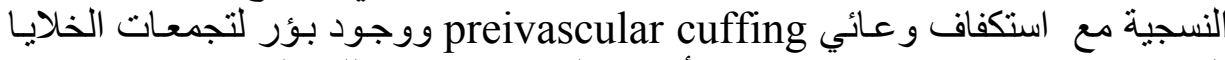
الدبقية Multifocal gliosis وخلايا أحادية النواة مع فقدان اللبد العصبي

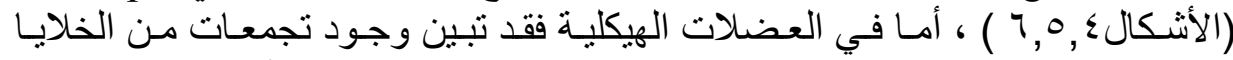

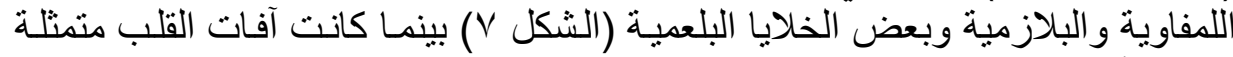

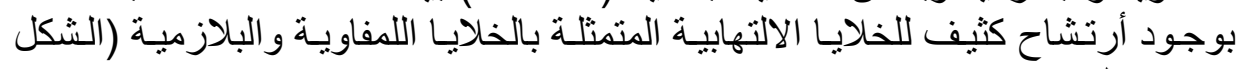
(^)، جدول) (0)

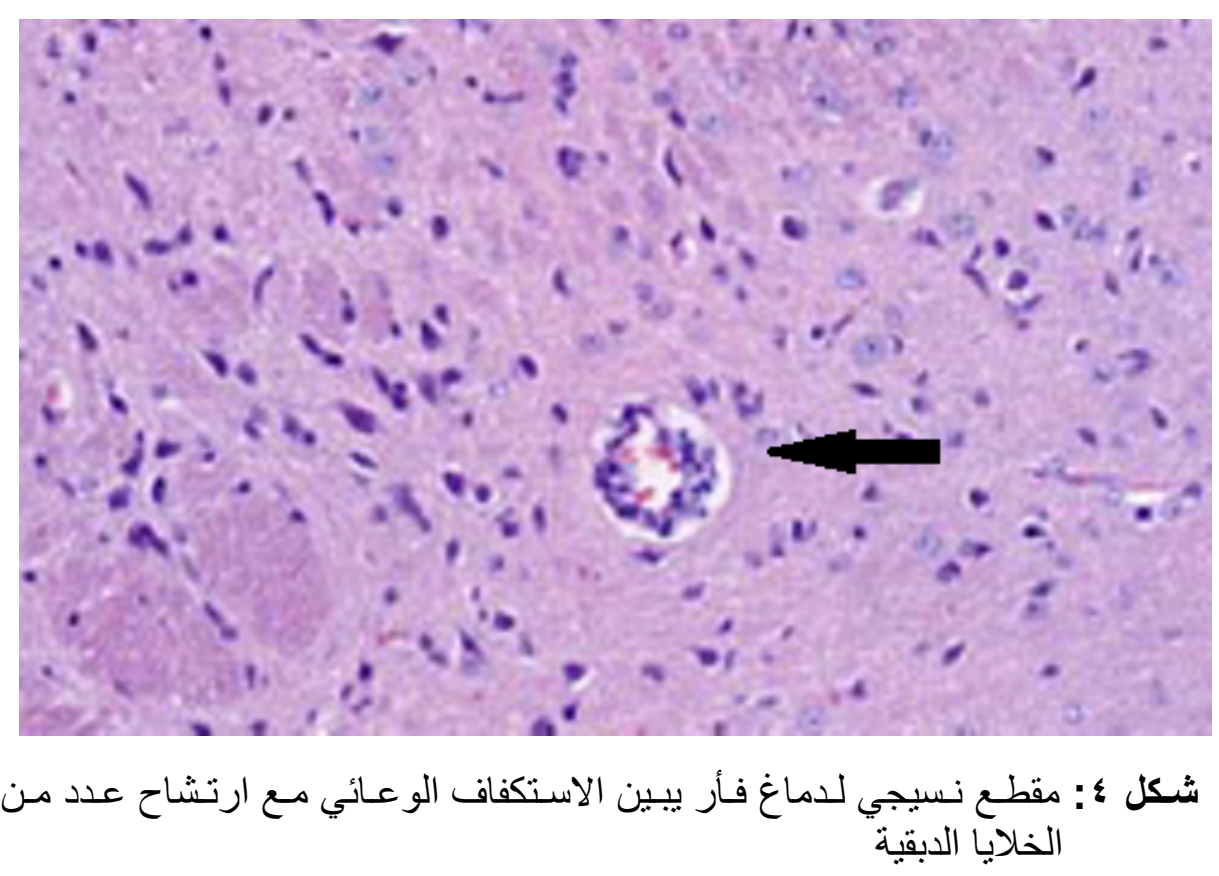




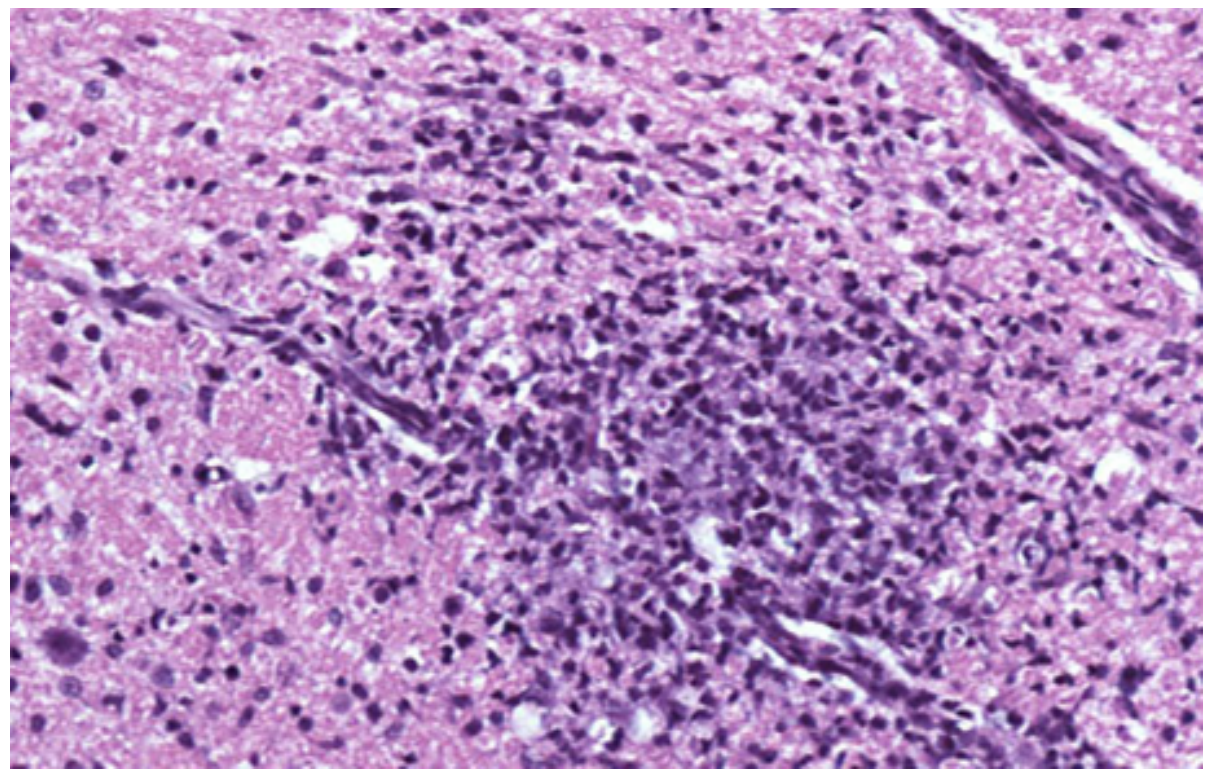

شكل •: مقطع نسيجي لدماغ فأر يبين فقدان اللبد العصبي Neuropil مع تجمع كثيف من الخلايا الدبقية وارتشاح خلايا أحادية النواة لإني 


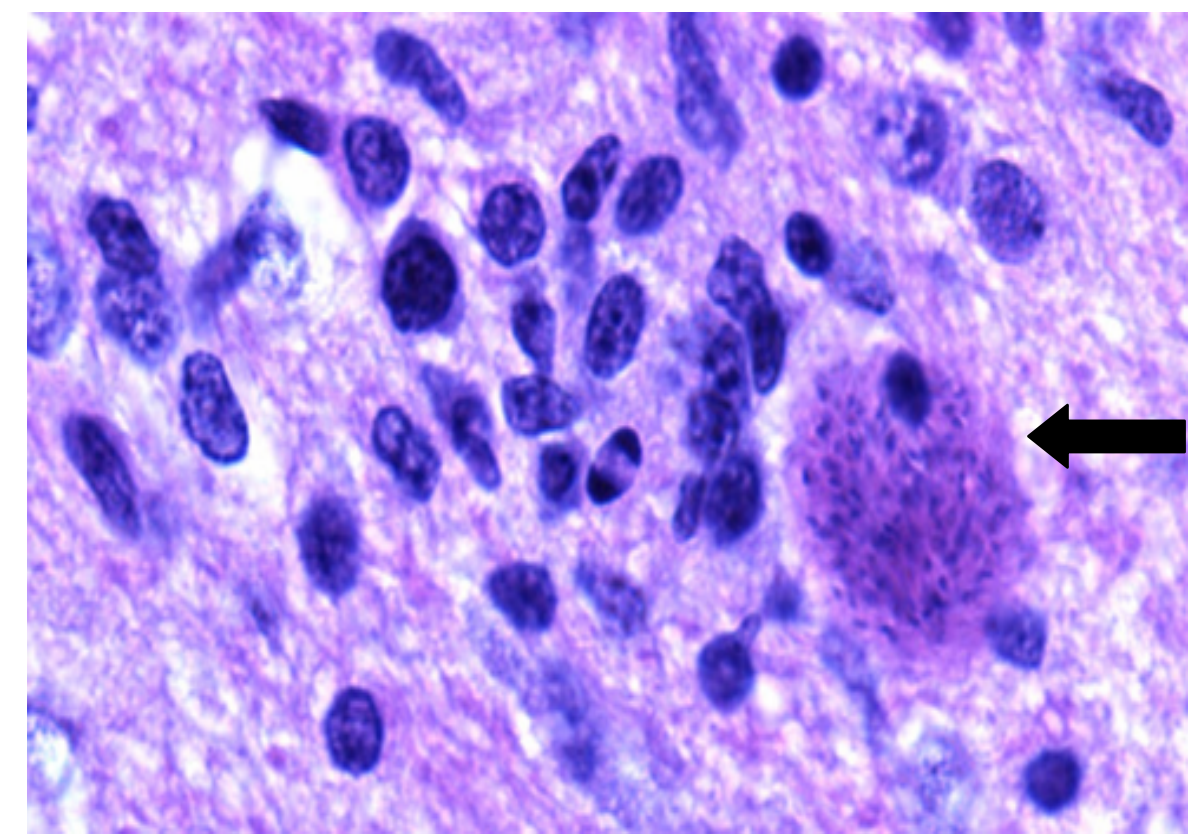

$$
\text { شكل })^{\prime} \text { : مقطع نسيجي لدماغ فأر يبين ظهور الكيس النسجي للطفيلي }
$$

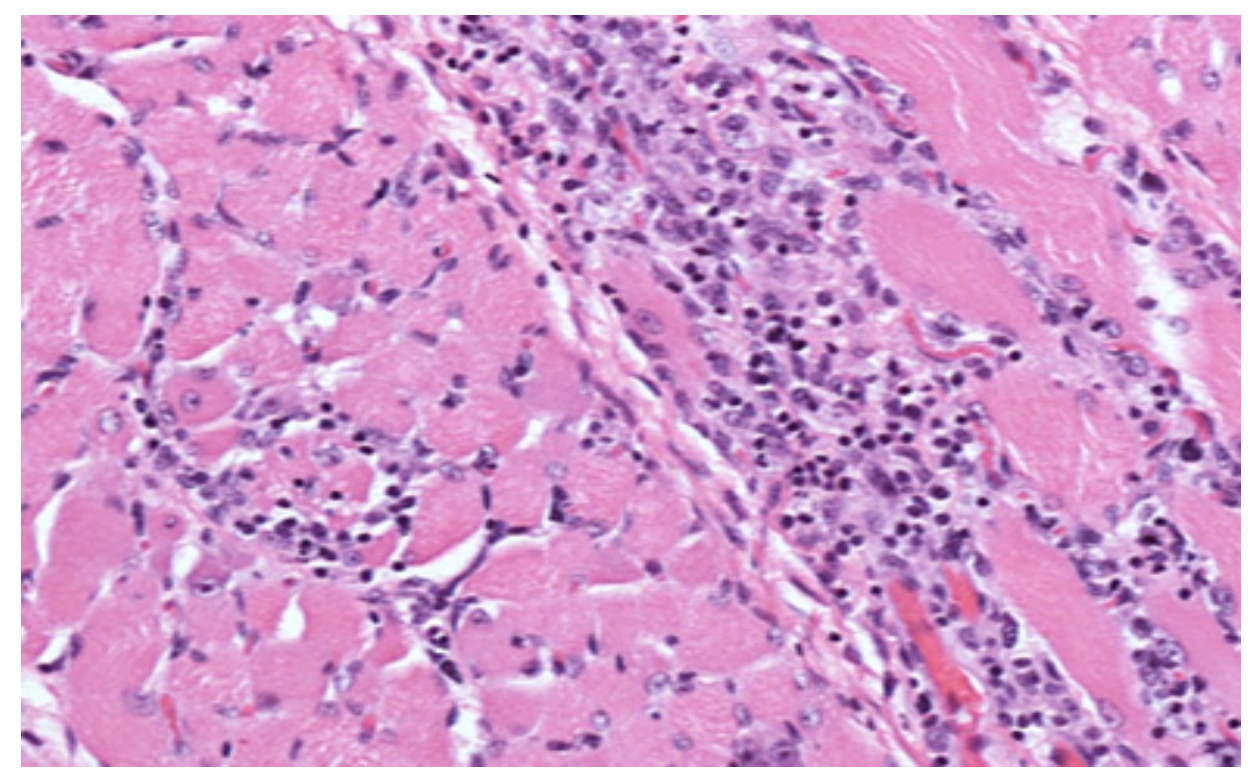

شكل V: مقطع نسيجي لعضلات هيكلية فأر يبين وجود تجمعات من الإنات

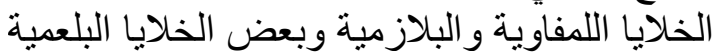




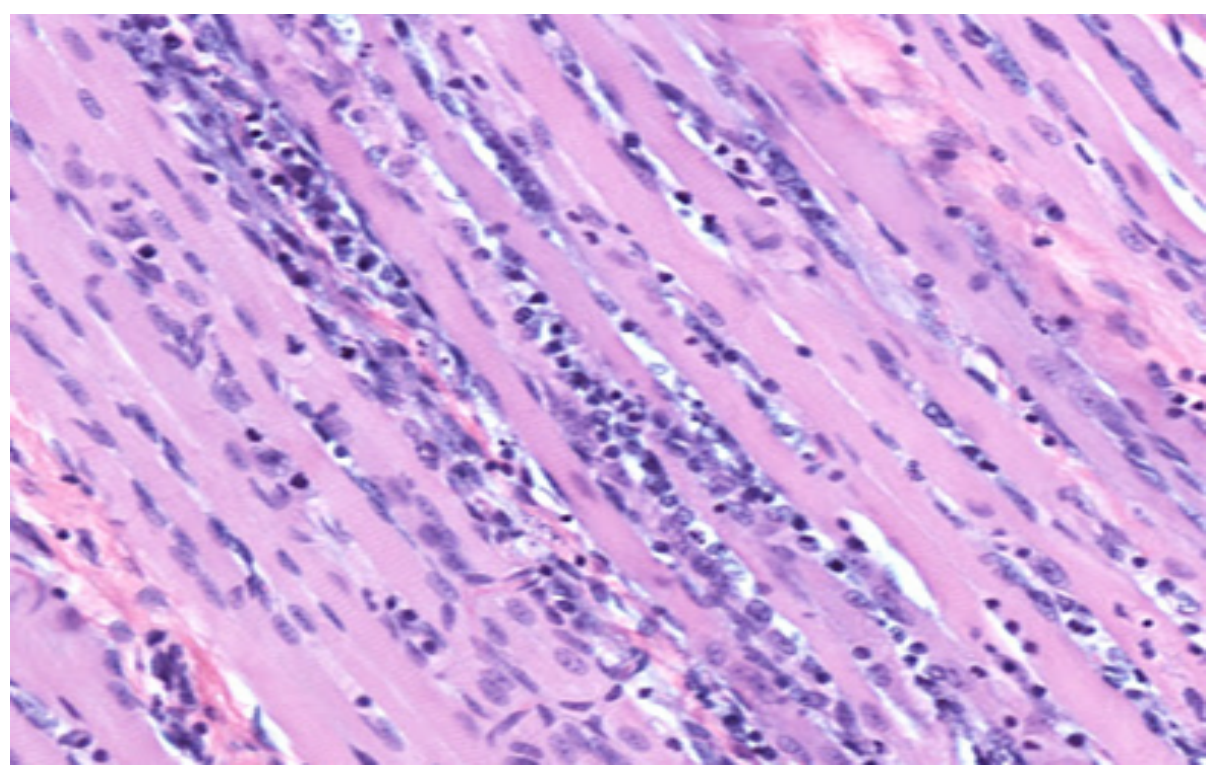

شكل ^: مقطع نسيجي لقلب فأر يبين وجود ارتشاح كثيف للخلايا الالتهابية المتمثلة بالخلايا اللمفاوية و البلازمية البية

جدول •: يبين ظهور الطفيلي في الأعضاء المختلفة للفئران قبل وبعد الحقن بالذراري الثنلاث باستخدام الفحص النسيجي

\begin{tabular}{|c|c|c|c|c|c|c|c|c|}
\hline 9. & 7. & $r_{\Lambda}$ & (I) & $1 \leqslant$ & V & . & 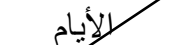 & \\
\hline+ & + & + & - & - & - & - & الدماغ & \multirow{3}{*}{ NC5 } \\
\hline+ & + & + & - & - & - & - & القلب & \\
\hline+ & + & - & - & - & - & - & الهيكلية & \\
\hline+ & - & - & - & - & - & - & الدماغ & \multirow[t]{3}{*}{$\mathrm{Nc1}$} \\
\hline+ & + & - & - & - & - & - & القلب & \\
\hline+ & - & - & - & - & - & - & الهيكلية & \\
\hline+ & + & - & - & - & - & - & الدماغ & \multirow[t]{3}{*}{ BPA4 } \\
\hline+ & + & - & - & - & - & - & القلب & \\
\hline+ & + & - & - & - & - & - & الهيكلية & \\
\hline
\end{tabular}




\section{DISCUSSION}

\section{المناقشة}

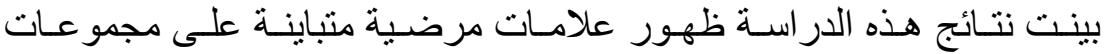

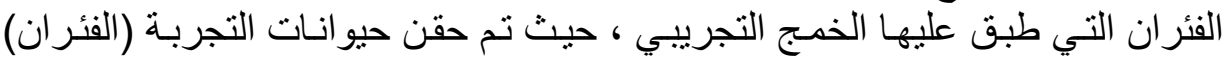

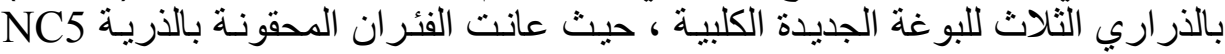

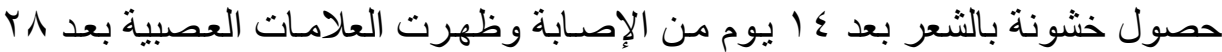

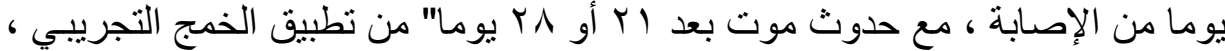

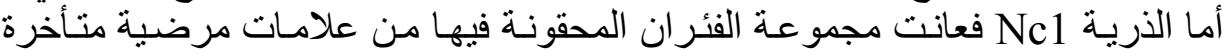

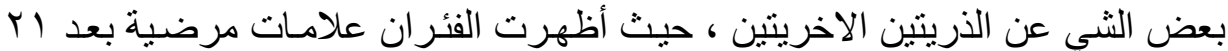

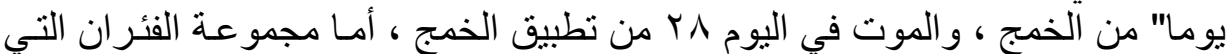

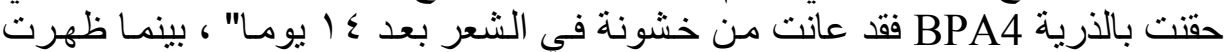
الأعر اض العصبية بعد · ب يوما.

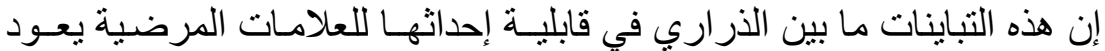

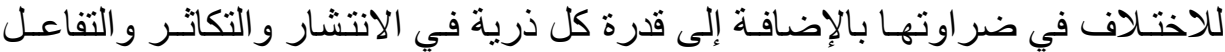

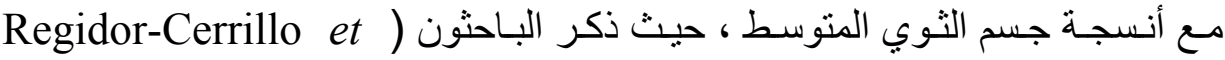

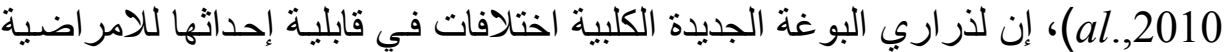

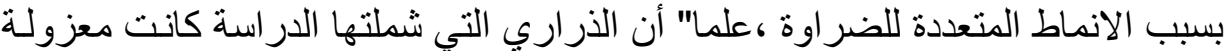

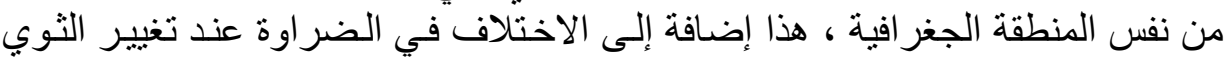

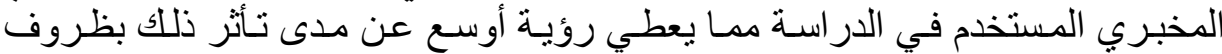

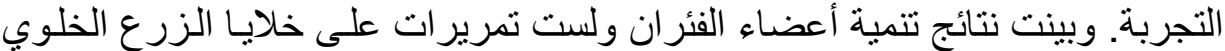

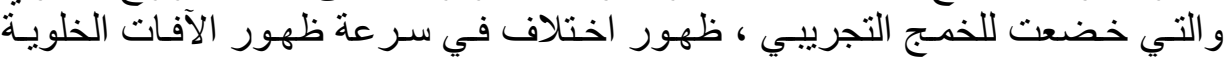

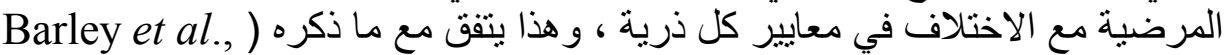

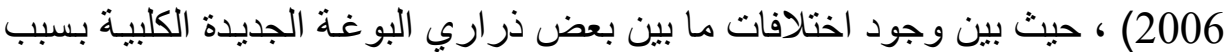

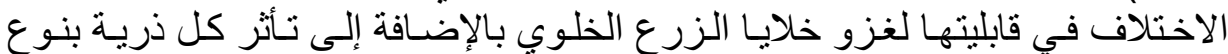

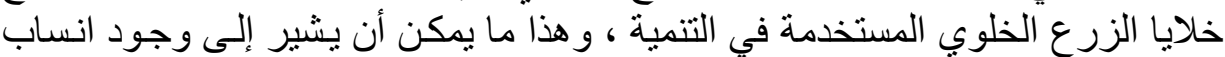

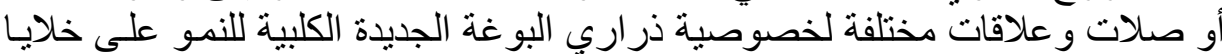

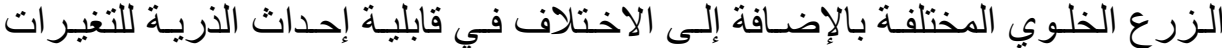
المرضية الخلويـة على خلايـا الزرع الخلوي، إذ بين (Cheah et al., 2004) ، في الإني

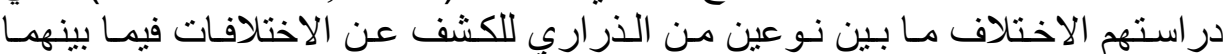

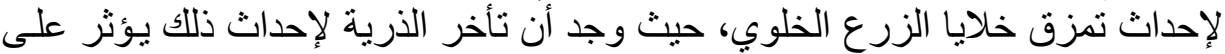

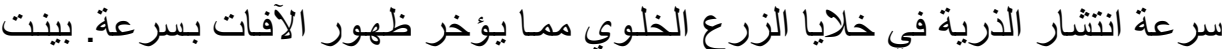

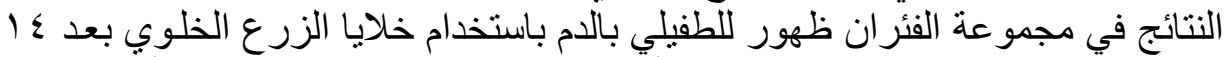

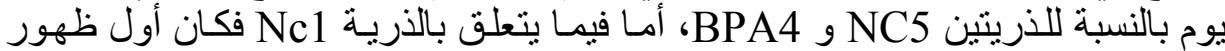

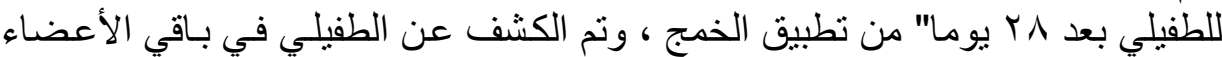


بعد ذللك الوقت ،إن هذه الاختلافات في زمن ظهور الطفيلي في الأعضاء يعود إلى هذي

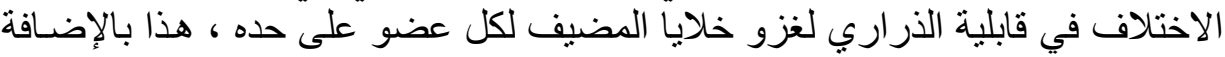

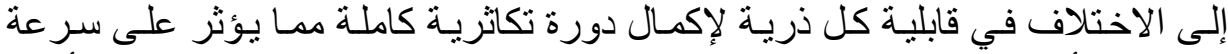

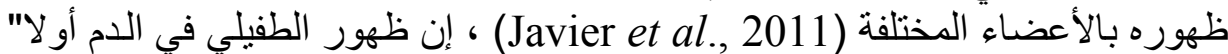

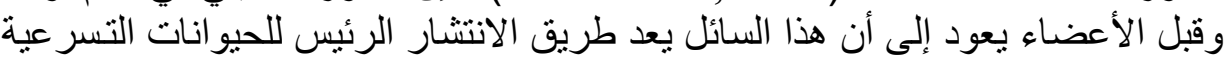

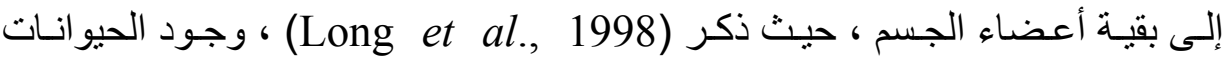

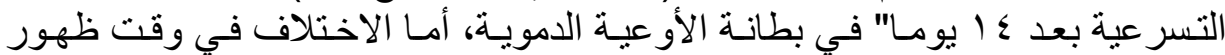

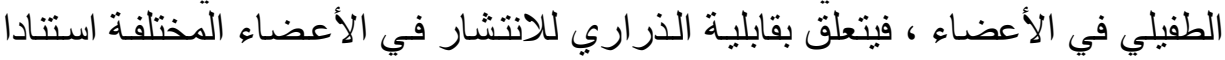

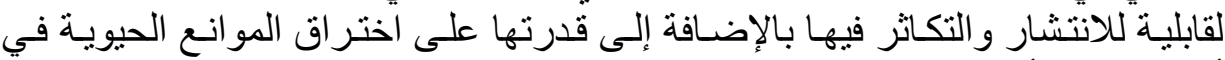

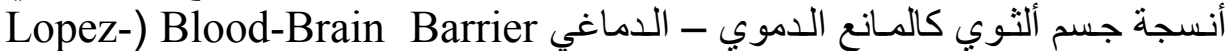
Perez et al., 2006 (أمـا نتائج الكشف عن ألدنا للطفيلي في المـزارع الخلويـة

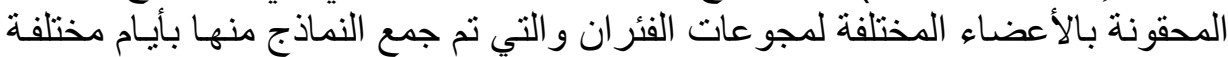

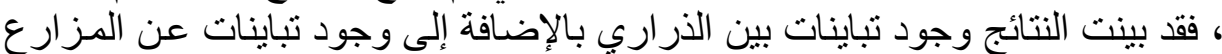

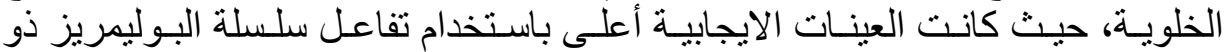

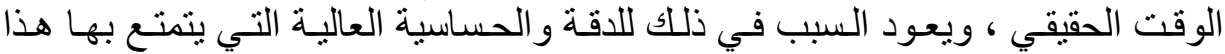

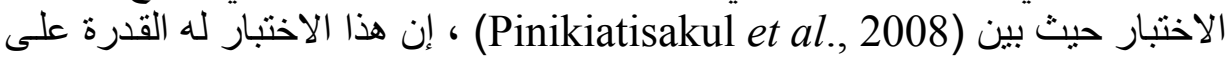

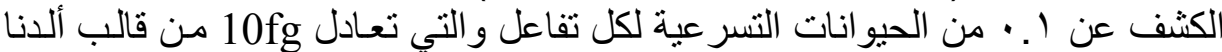
للبو غة الجديدة الكلبية ، حيث بين وجود عينـات سلبية للبو غـة الجديدة الكلبية باستخدام

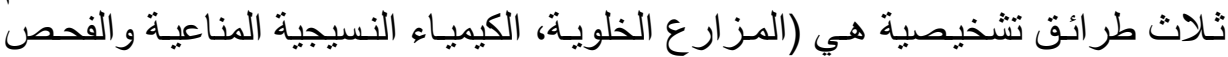

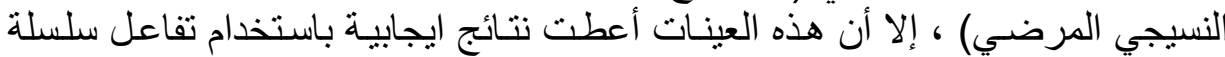

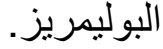

فيما بينت نتائج الفحص النسيجي لأعضاء الفئران المحقونـة تأخر ا في ظهور

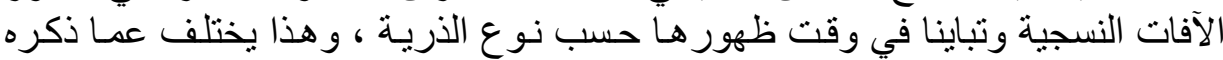

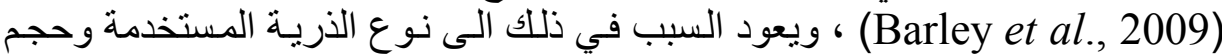
الجرعة التي خمج بها من الحيو انات التسر عية.

أن عدم التو افق في نتائج الكشف عن ضدراوة الذراري المختلفة مـع در اسـات

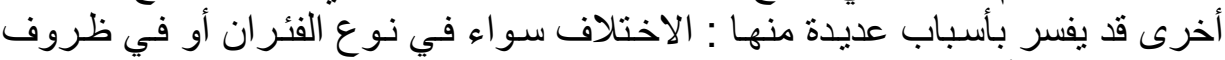

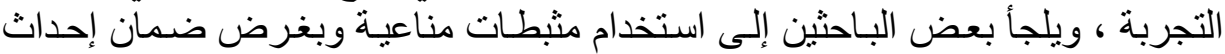

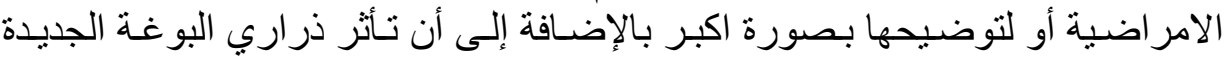

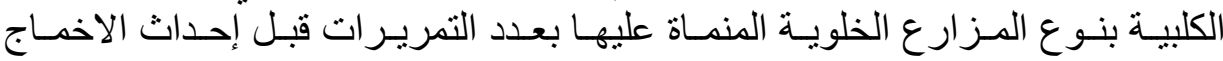

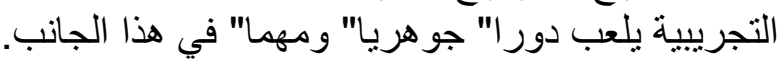

\section{REFERENCES}

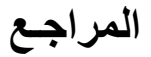


Arabic References المراجع العربية

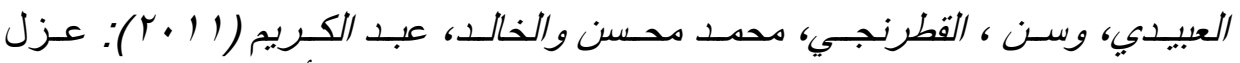

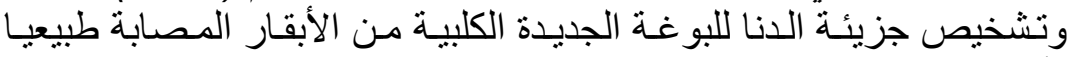

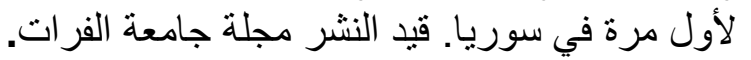

\section{المراجع الانكليزية Emglish References:}

Barber, J.S.; Holmdahl, O.J.; Owen, M.R.; Guy, F.; Uggla, A. and Trees, A.J. (1995): Characterization of the first European isolate of Neospora caninum .Parasitology,111: 563-568.

Barley, P.M.; Wright, S.; Sales, G.; Chianin, F.; Buxton, D. and Innes, E.A. (2006): Long-term passage of tachyzoites in tissue culture can Attenuate virulence of Neospora caninum in vivo. Parasitology, 133: 421-432.

Beck, H.P.; Blake, D.; Darde, M.L.; Flager, I.; Pedraza-Diaz, S.; Regidor-Cerrillo, J.; Gomez-Bautista, M.; Ortega-Mora, L.M.; Putignani, L.; Shiels, B.; Tait, A. and Weir, W. (2009): Molecular approach To diversity of populations of apicomplexan parasites. Int. J. Parasitol, 39: 175-189.

Chanatal, R.; Thierry, L.; Francois, D.M.; Charles, F. and Betrand, L. (2004): Survival, immune responses and tissue cyst Production in outbred (Swiss white) and inbred $(\mathrm{CBA} / \mathrm{Ca})$ Strains of mice experimentally infected with Neospora Caninum tachyzoites.Vet. Res, 35: 225-232.

Cheah, T.S.; Mattsson, J.G.; Zaini, M.; Sani, R.A.; Jakubek, E.B.; Uggla, A.; and Chandraawathani, P. (2004): Isolation of Neospora caninum From a calf in Malaysia. Vet. Parasitol, 29: 263-269.

Collantes-Fernandez, E.; Alvarez-Garcia, G.; Perez-Perez, V.; Pereia-Bueno, J. and Ortega-Mora, L.M. (2004): Characterization and pathology and parasite load in outbred and inbred Mouse models of chronic Neospora caninum infection. J. Parasitol., 90: 579-583.

Collantes-Fermandez, E.; Lopez-Petez, I.; Alvarez-Garcia, G. and Ortega-Mora, L.M. (2006): Tempral distribution and 
parasite Load kinetics in blood and tissue during Neospora caninum Infection in mice. Infect Immune, 74: 2491-2494.

Dubey, J.P.; Schares, G. and Ortega-Mora, L.M. (2007): Epidemiology and control of neosporosis and Neospora caninum. Clin Microbiol. Rev., 20: 232-367.

Esther, C.F.; Angel, Z.; Gema, A.G. and Luis, M.O. (2002): Quantitative detection Of Neospora caninum in bovine aborted fetuses and experimental Infected Mice by RealTime PCR.Journal Of Clinical Microbiolog,40(4): 1194-1198.

Hemphill, A.; Vanbufen, N. and Naguleswaaran, A. (2006): Cellular and Immunological basis of the host parasite relationship During infection with Neospora caninum. Parasitology, 133: 261-278.

Javier, R.; Mercedes, G.; Itsaso, S.; Gorka, A.; Gema, A.; Itziar, D. and Luis, M.A. (2011): In vitro invasion efficiency and intracellular and Proliferation rate comprise virulence related phenotypic Traits of Neospora caninum. Vet. Res., 42: 41-52.

Long, M.T.; Bszler, T.V. and Mathison, B.A. (1998): Comparison of Intracerebral parasite load, lesion development, and systemic Cytokins in mouse strains infected with Neospora caninum. J. Parasitol., 90: 579-583.

Lopez-Petez, C.; Risco-Castillo, V.; Collantes-Fermandez, E. and Ortega-Mora, L.M. (2006): Comparative effect of Neospora caninum Infection in balb/c mice ate three different gestation period. J. parasitol, 92: 1286-1291.

Masumi, S.; Hisayo, K.; Yukiko, T.; Chun-Ho, P.; Takehito, M.; Akinori, S. and Takashi, U. (2000): Isolation of Neospora caninum from the brain of a naturally infected adult dairy cow. Veterinary Parasitology, 90: 247-252.

Nathalie, V. (2003): Hiding inside the host: Development and application of Neospora caninum bradyzoites in vitro culture. PhD. Thesis, University of Basel, Germany, PP: 29-34. 
Pinikiattisakul, S.; Mattsson, J.G. and Lunden, A. (2008): A quantitative Analysis of parasite DNA in blood of immunized and native Mice after infection with Neospora caninum. Parasitology, 135: 175-182.

Quinn, H.F.; Miller, C.M.; Ryce, C.; Windsor, P.A. and Ellis, J.T. (2002): Characterization of an outbred pregnant mouse model of Neospora caninum infection. J. Prarsitol, 88: 691-696.

Regidor-Cerrillo, J.; Gomez-Bautista, M.; Del Poza, I.; JimenezRuiz, E.; Aduriz, G. and Ortega-Mora, M. (2010): Influence of Neospora Caninum intra-specific variability in the outcome of infection in a Pregnant Balb/c mouse model.Vet. Res., 41: 52-58.

Rojo-Montejo, S.; Collantes-Fermandez, E.; Regidor-Cerrillo, J.; Alvarez-Garcia, G.; Marugan-Hernandez, V.; PedrazaDiaz, S.; Blanco-Murcia, J.; Prenafeta, A. and OrtegaMora-L. M. (2009): Isolation and characterization of bovine isolate of Neospora Caninum with low virulence. Vet. Parasitol, 159: 7-16.

Yamane, I.; Kokuho, T.; Shimura, K.; Eto, M.; Shibahara, T.; Haritani, M.; Ouchi, Y.; Sverlow, K. and Conrad, P.A. (1997): In Vitro isolation and Characterization of a bovine Neospora Species in Japan. Res. Vet. Sci., 63: 77-80.

Shibahara, T.; Kokuho, M.; Eto, M.; Haritani, T.; Hamaoka, K.; Shimura, K.; Nakamura, Y. and Yamane, I. (1999): Pathological and Immunological finding of athymic nude and congonic wild Type Balb/c mice experimentally infected with Neospora Caninum. Vet. Pathol., 36: 321-327. 